\author{
RESEARCH ARTICLE \\ 10.1029/2018JC014738 \\ Key Points: \\ - Low frequency open ocean impact on \\ the North Sea is revealed in a global \\ coupled model \\ - The properties of Atlantic inflow \\ to the North Sea follow changes in \\ subpolar gyre strength, while the \\ total inflow is wind driven \\ - The subpolar gyre signal in the \\ Faroe-Shetland Channel and the \\ North Sea is more pronounced in \\ salinity than in temperature
}

Correspondence to:

V. Koul,

vimal.koul@uni-hamburg.de

Citation:

Koul, V., Schrum, C., Düsterhus, A., \& Baehr, J. (2019). Atlantic inflow to the North sea modulated by the subpolar gyre in a historical simulation with MPI-ESM. Journal of Geophysical Research: Oceans, 124, 1807-1826. https://doi.org/10.1029/2018JC014738

Received 7 NOV 2018

Accepted 23 FEB 2019

Accepted article online 5 MAR 2019

Published online 20 MAR 2019

\section{Atlantic Inflow to the North Sea Modulated by the Subpolar Gyre in a Historical Simulation With MPI-ESM}

\author{
V. Koul ${ }^{1,2}$ iD, C. Schrum ${ }^{1,3}$, A. Düsterhus ${ }^{1}$ iD, and J. Baehr ${ }^{1}$ (D) \\ ${ }^{1}$ Institute of Oceanography, Center for Earth System Research and Sustainability, Universität Hamburg, Hamburg, \\ Germany, ${ }^{2}$ International Max Planck Research School on Earth System Modelling, Max Planck Institute for \\ Meteorology, Hamburg, Germany, ${ }^{3}$ Institute of Coastal Research, Helmholtz Zentrum Geesthacht, Geesthacht, Germany
}

\begin{abstract}
While the influence of the subpolar gyre (SPG) on thermohaline variability in the eastern North Atlantic is well documented, the extent and timescale of the influence of the SPG on North Sea is not well understood. This is primarily because earlier investigations on the causes of variability in the North Sea water properties mostly focused on the role of atmosphere and deployed regional models. Here using a historical simulation with the Max Planck Institute Earth System Model (MPI-ESM), we investigate circulation and water mass variability in key regions, namely, the Rockall Trough and the Faroe-Scotland Channel, which link the North Atlantic to the North Sea. We find that salinity covaries with advective lags in these three regions and that the northern North Sea salinity follows the Rockall Trough with a lag of 1 year. We show that recurring and persistent excursions of salinity anomalies into the northern North Sea are related to the SPG strength and not to the local acceleration of the inflow. Furthermore, we illustrate that the SPG signal is more pronounced in salinity than in temperature and that this simulated SPG signal has a period of 30-40 years. Overall, our study suggests that, at low frequency, water mass variability originating in the North Atlantic dominates changes in the North Sea water properties over those due to local wind-driven volume transport.
\end{abstract}

Plain Language Summary Earlier investigations on the causes of variability in the North Sea water properties have mostly focused on the role of the atmosphere. This follows from the general idea that shallowness of the North Sea makes it more responsive to wind speed and direction than the deeper ocean. In the present contribution, we identify variability in North Sea water properties other than that induced by the atmosphere. For our analysis, we use a historical simulation with a global coupled model for two reasons: (a) In the model, the connections between North Atlantic and North Sea are represented, which would not be the case in a regional model, and (b) the model provides a long continuous time series of water properties, which is not available from spatially and temporally scarce observations. We find that the strength of subpolar gyre (SPG) has an impact on the salinity of the North Sea. When the SPG is weak (strong), water from the subtropical (subpolar) North Atlantic dominates the inflow into the North Sea and thus increasing (decreasing) the salinity. This modulation of inflow properties happens at decadal periods and beyond and is largely independent of the amount of Atlantic water entering the North Sea.

\section{Introduction}

The North Sea is a shallow adjacent sea of the Atlantic Ocean located on the Northwestern European continental shelf (NWES). The northern boundary of the North Sea presents an opening for water masses of Atlantic origin to propagate into this region. However, before entering the North Sea, these oceanic anomalies mainly pass through two key upstream regions: the Rockall Trough and the Faroe-Shetland Channel (FSC). The Atlantic inflow through these key regions draws water masses from the North Atlantic Current (NAC), the European Slope Current (ESC), and also from the East Icelandic Current (EIC) north of the FSC (Turrell et al., 1996). Therefore, hydrographic changes in the North Sea have often been shown to be influenced by water mass variability originating in the key upstream regions (Holliday \& Reid, 2001; Núñez-Riboni \& Akimova, 2017). However, given observational and modelling constraints, a robust spatial and temporal characterization of the influence of the North Atlantic on the North Sea is still missing.
(C)2019. American Geophysical Union. All Rights Reserved. 
Earlier investigations have mostly focused on the atmosphere-driven North Sea variability, and regional models have been used preferably (see, for example, Daewel \& Schrum, 2017; Hjøllo et al., 2009; Winther \& Johannessen, 2006). This is because the shallowness of the North Sea makes it more responsive to overlying atmospheric variability. However, being able to identify a variability of North Atlantic (oceanic) origin has the advantage that it not only explains part of the variability in marine ecosystems (Akimova et al., 2016; Holt et al., 2012), but it can also lead to long term hydrographical and biogeochemical predictability. Therefore, of particular interest has been to understand which part of variability in the North Sea is of Atlantic origin (Alheit et al., 2014; Holliday \& Reid, 2001). Hence, given the nature of the problem, recent studies have highlighted added value in simulating North Atlantic-North Sea connections using global models (Mathis et al., 2017; Pätsch et al., 2017). This approach has the advantage that it allows a dynamically consistent representation of North Atlantic-North Sea connections and circumvents the issues associated with specifying lateral boundary conditions in regional models.

The motivation to investigate North Atlantic-North Sea connection in a global coupled model also stems from the fact that no robust conclusion could be drawn from the few observational studies concerning long-term North Atlantic-driven variability in the North Sea. For example, by analyzing 65-year surface salinity data for the NWES, Dickson (1971) concluded that the advection of higher proportion of subtropical water was responsible for extended periods of high salinity in the NWES. He linked the periodicity and sustained salinification of the NWES to a persistent pressure-anomaly pattern, which was then shown to induce sustained advective changes in the eastern North Atlantic. Becker and Dooley (1995) attributed the 1989/1990 high salinity event in the North Sea to increased inflow of Eastern North Atlantic Water (ENAW) in the ESC. They conjectured that large scale circulation changes were responsible for reorganization of water masses in the eastern North Atlantic, which in turn had an impact on the inflow stream to the North Sea. While these studies suggest that the causes of salinification events in the NWES are not attributable to a single mechanism, the multiyear persistence of such events also suggests that the causes and characteristics of the large-scale oceanic variability, which leads to salinification in the NWES, need further investigation.

In the upstream region, that is, the eastern North Atlantic, abundant observational evidence suggests a role of subpolar gyre (SPG) variability in driving thermohaline changes (Bersch, 2002; Hátún et al., 2005; Holliday, 2003; Sarafanov et al., 2008). A weak SPG circulation allows northward penetration of subtropical water. In the Rockall Trough, long-term observations also suggest an overall warming and salinification from late 1990s till mid-2000s (Holliday et al., 2015), linked to the SPG variability (Sherwin et al., 2011). The SPG-driven changes that have occurred in the Rockall Trough are not limited to thermohaline properties alone; for example, links with nutrient concentrations have also been reported (Johnson et al., 2013). Modeling studies have further suggested that the SPG strength undergoes decadal changes and the mid-1990s event was part of that decadal variability (Böning et al., 2006; Zhang, 2008). Therefore, anomalous SPG circulation is thought to control the proportion of subtropical and subpolar water masses in the Atlantic inflow across the Iceland-Scotland Ridge (ISR).

The SPG-driven thermohaline variability in the Rockall Trough, the FSC, and the North Sea has not yet been examined in a global model. Hjøllo et al. (2009) did point out that some of the discrepancies in simulating salinity variability at northern North Sea stations in their regional model arose due to the imposed boundary conditions and the limited domain of their model, both of which tend to disregard the SPG signal from open ocean. Using a global model, Mathis et al. (2017) highlighted the importance of North Atlantic in driving future changes in the NWES. Thus, there seems to be some hint that the impact of dynamic circulation changes in the North Atlantic extends to the North Sea. However, a comprehensive analysis of the relationship between variability in SPG circulation and Atlantic inflow to the North Sea has remained unexplored.

In the present contribution, we examine North Atlantic-North Sea connections in a historical simulation with a global coupled model. Our aim is to reveal the spatial and temporal characteristics of the influence of the SPG on North Sea properties in such a century long simulation. We use a combination of correlation, composite and water mass analysis to study the key region.

Section 2 describes the model and methods used, results are provided in section 3, section 4 discusses the main findings, and conclusions are presented in section 5. 


\section{Model Details, Methods, and Model Evaluation}

\subsection{Model Details}

The Max Planck Institute Earth System Model (MPI-ESM) version 1.2 is the latest version of the global Earth system model developed at the Max Planck Institute for Meteorology and is used in its low-resolution (LR) setup in the present study (hereafter MPI-ESM1.2-LR). The ocean general circulation component of MPI-ESM1.2-LR, the Max Planck Institute Ocean Model (MPIOM; Jungclaus et al., 2013), is a free surface model with primitive equation solved on an Arakawa $\mathrm{C}$ grid and with hydrostatic and Boussinesq approximations. It has a total of $40 \mathrm{z}$ levels in the vertical with closely spaced upper levels; the surface layer thickness is $12 \mathrm{~m}$. Formulations by Pacanowski and Philander (1981) are followed for vertical mixing and diffusion, and tracer transport is parameterized following Gent et al. (1995). Statically unstable flow over sills and shelves is represented by a slope-convection scheme (Marsland et al., 2003). The MPIOM setup used in the study has a rotated grid configuration (GR15) for which the singularity at the North Pole is replaced over Greenland. This has the advantage that horizontal resolution is enhanced north of $50^{\circ} \mathrm{N}$, reaching $15 \mathrm{~km}$ near Greenland. The resolution increases gradually to $1.5^{\circ}$ toward the equator. Embedded in MPIOM is also the ocean biogeochemistry component, the Hamburg Ocean Carbon Cycle model (Ilyina et al., 2013). Among other processes, Hamburg Ocean Carbon Cycle incorporates phosphate and oxygen cycles, and defines the marine food web based on nutrients, phytoplankton, zooplankton, and detritus-based approach.

The atmospheric general circulation component of MPI-ESM1.2-LR is the European Center-Hamburg (ECHAM; Stevens et al., 2013). In MPI-ESM1.2-LR, the ECHAM is run at a horizontal resolution of T63 and with 47 vertical levels, the model top being at $0.01 \mathrm{hPa}$. The land surface-atmosphere interactions are simulated by the land vegetation module JSBACH (Reick et al., 2013), which is embedded in ECHAM. A land hydrology module that contains a river-routing scheme is used for interactive simulation of river runoff (Hagemann \& Gates, 2003). MPIOM receives the fresh water fluxes due to river runoff as part of the precipitation field from ECHAM.

\subsection{Methods}

In this study, we analyze a historical simulation performed under natural and anthropogenic forcings derived from observations covering a total of 156 years (1850-2005). The natural forcing includes solar insolation, variations of the Earth orbit, tropospheric aerosol, stratospheric aerosols from volcanic eruptions, and seasonally varying ozone. The anthropogenic forcing includes the well mixed gases $\mathrm{CO}_{2}, \mathrm{CH}_{4}, \mathrm{~N}_{2} \mathrm{O}$, CFC-11, and CFC-12 as well as $\mathrm{O}_{3}$ and anthropogenic sulfate aerosols. Tides are not taken into account in this simulation. Atmospheric $\mathrm{CO}_{2}$ concentrations are prescribed and the carbon cycle is not interactive. It must be noted that as this historical simulation is not initialized from observations, the internal variability in this model simulation may not be in phase with observations and hence may not reproduce the observed timing of certain climatic events, which are related to internal (natural) variability. However, dynamical relationship between variables of interest within the model can be compared to their observed relationship (Langford et al., 2014; Martin et al., 2014; Zhang \& Wang, 2013). This simulation provides the base for understanding spatial and temporal modes of variability and their connections with North Sea. Here we focus on the relation between SPG circulation and North Sea variability and if similar relationship is seen in observations.

Annual mean values of model output variables are first computed and detrended (linear trend is removed at each grid point) prior to subsequent analysis. Anomalies are calculated by removing the mean of the entire simulation period (1850-2005). The climatological (1850-2005 mean) bias of modeled salinity is calculated against Climate Water Navigation (KLIWAS) North Sea Climatology data set (1873-2013 mean) available from Integrated Climate Data Center (https://icdc.cen.uni-hamburg.de/ 1/daten/ocean/knsc-hydrographic.html).

Throughout this study, correlation coefficients are calculated from detrended anomalies. To estimate the uncertainty in correlation, we modify the strategy of McCarthy et al. (2015) wherein they use a parametric and a nonparametric approach. As the data are autocorrelated, we first calculate the effective degrees of freedom. For this, we use the equation given by Pyper and Peterman (1998) to determine the degree of freedom on the basis of autocorrelation coefficients at various lags.

For the nonparametric approach, we use block bootstrapping. While the $t$ test assumes the data to be normally distributed, the block bootstrap method does not make such an assumption. In this method, a set of 10,000 bootstrap samples, each having the same length as the parent time series, is constructed by blockwise 

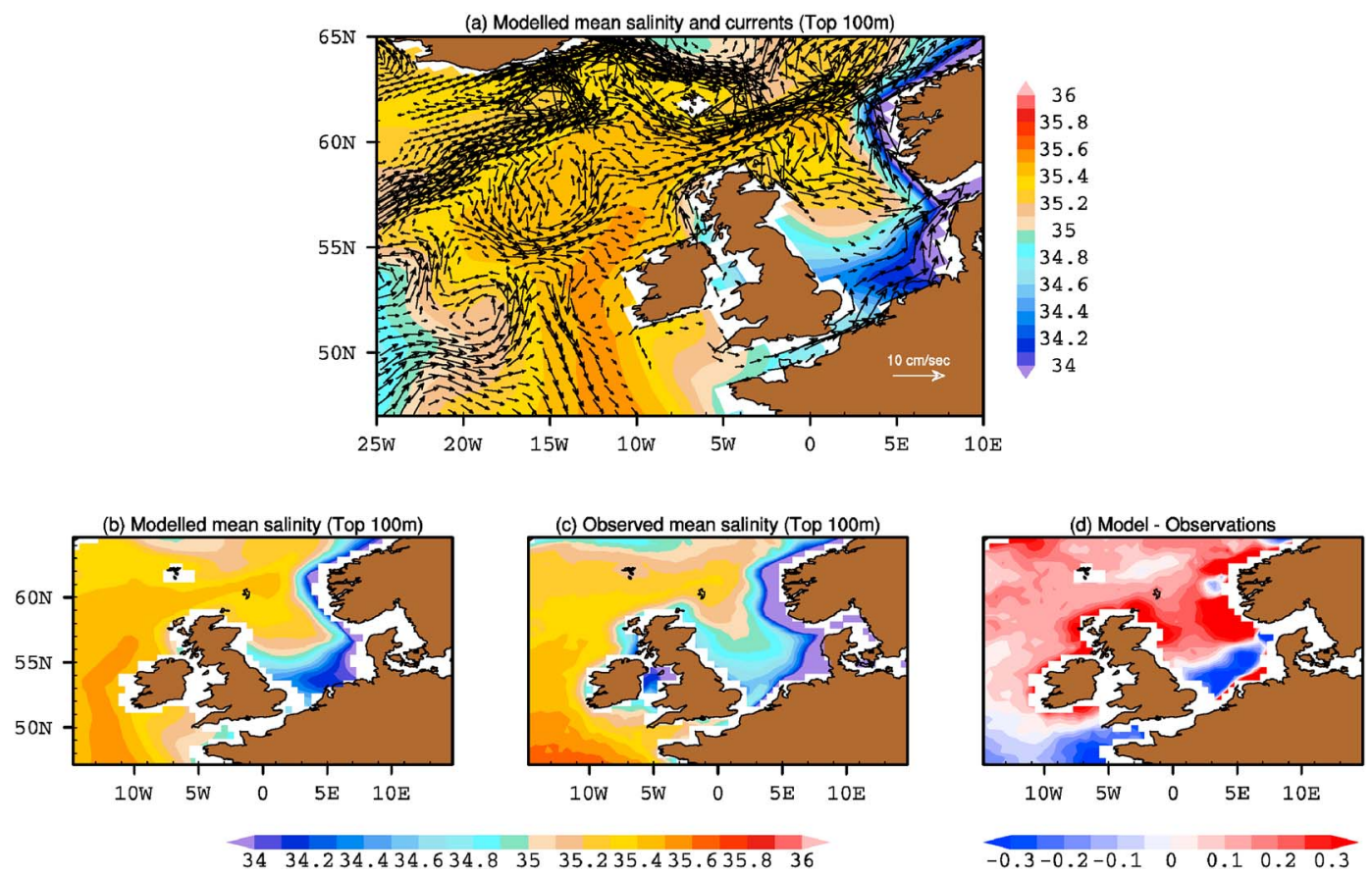

Figure 1. (a) Modeled mean salinity (psu, color) and currents (cm/s, arrows) averaged over top $100 \mathrm{~m}$ of the water column. Current vectors $<1 \mathrm{~cm} / \mathrm{s}$ are not shown. (b) Modeled mean, (c) observed (KLIWAS North Sea Climatology) mean, and (d) bias of salinity (psu) in the Northwestern European continental shelf region.

sampling with replacement from the parent time series. The block length $L$ is given by $\left(L=\frac{N}{\min \left(N^{*}\right)}\right)$, where $N^{*}$ is the effective degrees of freedom and $N$ is the length of the time series. This choice of block length ensures that the most conservative estimate of confidence intervals is obtained. The resulting distribution of correlations is then investigated for significance. The sensitivity of the significance bounds to block length is also tested by changing the block length to a higher and lower value; we find that the result remains almost unchanged. The uncertainty in the time lag of maximum correlation is estimated by the time at which the median of block bootstrapped correlations is greater than the lower bound of the confidence interval derived from the block bootstrapping.

We define the index of SPG strength as the principal component of the leading mode of annual mean (detrended) sea surface height $(\mathrm{SSH})$ anomaly over North Atlantic $\left(0-70^{\circ} \mathrm{W}, 30-65^{\circ} \mathrm{N}\right)$. Read together with the weights of the leading mode in the central SPG region (Figure 6), the positive values of this index (hereafter SPGI) correspond to an increase in the SSH and thus represent a weak SPG. Using altimeter data and ocean model hindcast, SPGI has previously been shown to represent variability in SPG strength (Häkkinen \& Rhines, 2004; Hátún et al., 2005) although the methodology for computing SPG index from SSH data is now being debated (Foukal \& Lozier, 2017; Hátún \& Chafik, 2018). The SPGI has also been shown to be a proxy for changes in SPG strength in a 2,000-year coupled model simulation (Zhang, 2008).

We also perform a regression analysis to reconstruct North Sea salinity using multiple predictors. As such, we first split the simulated North Sea salinity time series into two parts: 1853-1950 and 1951-2005. Regression coefficients are estimated from the former time period, and the same coefficients are then used to reconstruct North Sea salinity for the later time period. The bootstrap procedure as described above is also used here to estimate the confidence bounds.

\subsection{Model Evaluation: North Atlantic-North Sea Connections in MPI-ESM1.2-LR}

To identify North Atlantic-North Sea connections in MPI-ESM1.2-LR, we first explore mean large-scale circulation patterns and salinity profiles in key regions. Earlier versions of this model have been shown to realistically represent the large-scale mean circulation in the North Atlantic (Jungclaus et al., 2013). Our analysis also suggests that the simulated mean upper ocean circulation in the North Atlantic in MPI-ESM1.2-LR (Figure 1) has qualitative resemblance with observations (e.g., Orvik \& Niiler, 2002). Consistent with observations, two branches of the NAC enter the eastern North Atlantic as the Iceland branch 
(a)

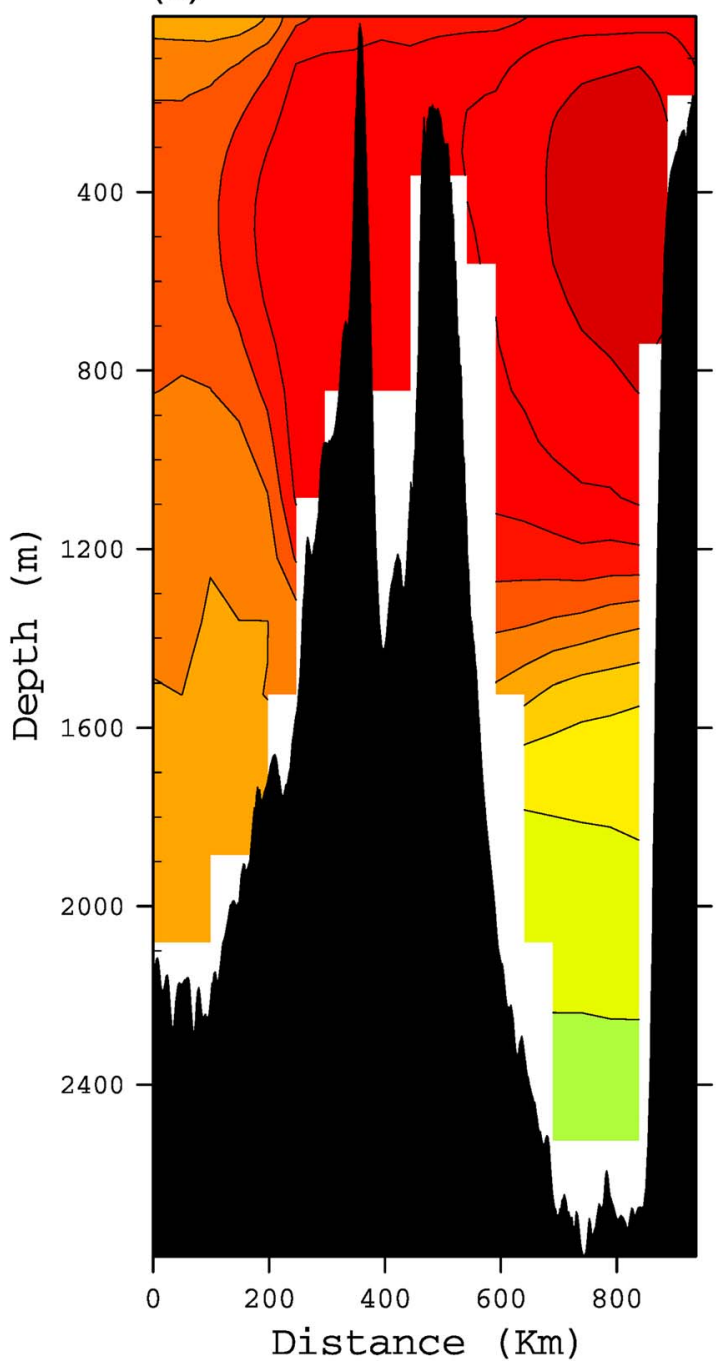

(b)

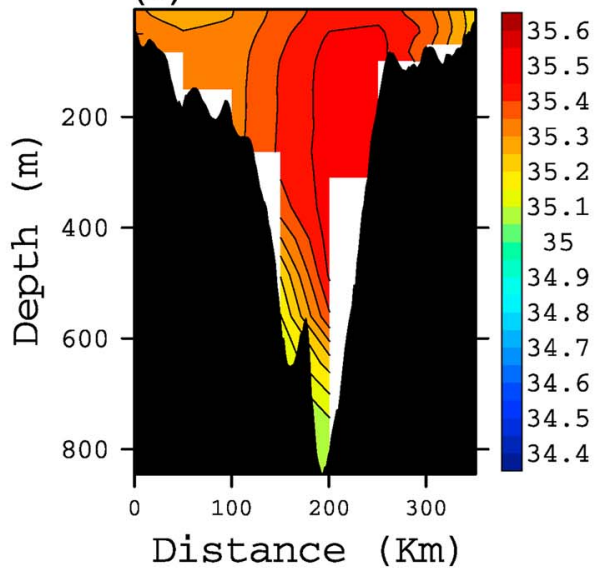

(c)

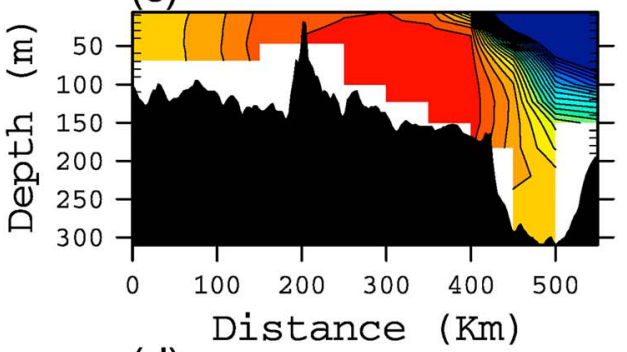

(d)

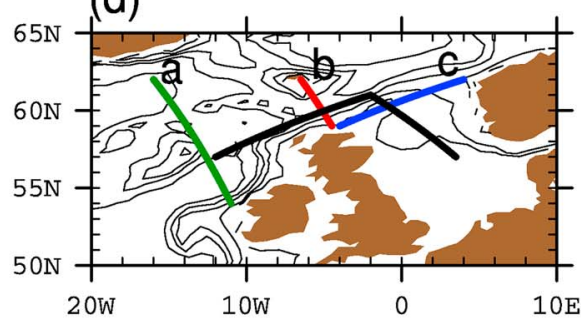

Figure 2. Salinity (psu) on a section across (a) Rockall Trough, (b) Faroe-Scotland Channel, and at (c) North Sea entrance. (d) The location of the various sections used in this study. Green: Rockall Trough, red: Faroe-Scotland Channel, and blue: North Sea entrance. The bold black line from Rockall Trough to central North Sea represents the section on which Figure 7 is based. The thin black lines in Figure 2d are the 100-, 200-, 1,000-, and 2,000-m isobaths.

and the Rockall Trough branch (Figure 1a). The Rockall Trough branch is, however, more diffused than what observations suggest (Orvik \& Niiler, 2002). Nevertheless, the Rockall Trough branch intensifies when it enters the FSC, which is also seen in observations. This model has a strong Iceland Branch, which turns eastward after crossing the ISR and feeds the FSC. A relatively weak yet continuous current that links northern Irish shelf to the North Sea is also simulated by the model.

The North Sea circulation is cyclonic with inflows from the wide open entrance in the north and from the English Channel in the south. The northern North Sea inflow comprises of three main inflows: the Fair-Isle inflow, the East Shetland inflow, and the Norwegian Trench inflow (Turrell et al., 1996). The Norwegian Trench inflow is known to contribute the most to the northern North Sea inflow (Winther \& Johannessen, 2006). In the model, this separation is not so distinct; however, the model is able to reproduce northern inflows that progress cyclonically toward the central North Sea. Strong inflows are present east of Scotland and also along the western side of the Norwegian Trench. The model also shows a fresh outflow along the whole Norwegian Trench.

Recently, Pätsch et al. (2017) carried out a thorough analysis of the performance of MPIOM (with a different grid configuration) in the North Sea. Their results suggest that MPIOM performs satisfactorily over most of the North Sea although with discrepancies near coasts. Note that while the MPIOM grid resolution in that 
study was higher than in the present study, the model was forced using observed meteorological forcings, and hence, air-sea interactions were not taken into consideration. A similar model configuration used by Mathis et al. (2017) is also unsuitable for the present analysis because, in that model configuration, air-sea interaction is considered over the eastern North Atlantic region only. Such configuration is unsuitable to examine the influence of SPG circulation on the North Sea because the SPG is strongly influenced by basinwide atmospheric variability. Therefore, given the global coupled model configuration used in the present study (see section 2.1), we focus on the SPG variability, the shelf break, and northern and central parts of the North Sea and exclude the coastal regions.

The simulated mean upper ocean salinity field is shown in Figure 1. Northward extension of saline subtropical water is seen in the eastern North Atlantic. In the North Sea, northern parts are largely influenced by Atlantic Water, and hence, salinity values here exceed $35.0 \mathrm{psu}$, while southern and coastal regions are mainly influenced by river runoff and are therefore relatively fresher. Moreover, Atlantic water entering from the northern opening has its maximum southward extent down to $55^{\circ} \mathrm{N}$ in the North Sea, beyond which Atlantic salinity signature is diluted by fresh water runoff to the North Sea.

Comparison of upper 100-m modeled mean salinity with observations suggests that the model overestimates salinity over most of the eastern North Atlantic (Figure 1d). Major challenges for the model are present in the Norwegian Trench outflow region and in the southern North Sea; however, both these regions are not the focus of the present study. The climatological salinity bias in the Rockall Trough, the FSC, and northern North Sea is relatively lower than near shallow coastal regions.

The hydrography and circulation in the key regions of eastern North Atlantic and the North Sea derived from the model are expected to resemble mean features of observations. Therefore, we examine subsurface salinity on three sections (see Figure $2 \mathrm{~d}$ for locations) in the eastern North Atlantic. In the eastern North Atlantic, the core of Atlantic inflow extends down to $800 \mathrm{~m}$ in the water column close to the Irish shelf edge (Figure 2a) and dilutes westward, thus resembling observations in this region (Holliday et al., 2015). This core is seen in the FSC close to the Scottish shelf edge extending down to $400 \mathrm{~m}$ (Figure 2b). Observation suggest that the saline Atlantic core is present much closer to the Scottish (Shetland) side of the FSC extending from the surface down to $300 \mathrm{~m}$ (Berx et al., 2013). The shoaling of saline core from the Rockall Trough to the FSC indicates that the inflow is guided by topography and geostrophically forced. In the model, the continuity of this saline core into the North Sea is first revealed at a zonal section between Scotland and Norway where high-salinity water extends till the western edge of the Norwegian Trench (Figure 2c). Here the most saline Atlantic water enters through the central parts of this section and fresh water leaves through the Norwegian Trench.

The analysis of subsurface velocity field shows that the two branches of NAC, the Iceland and Rockall Trough branch, extend deeper down in the water column in the Iceland basin and shallower in the Rockall Trough, respectively (Figure 3a). As noted earlier, the Rockall Trough branch is more sluggish than the Iceland branch in this model simulation. The intensification of Rockall Trough branch is also revealed when it enters the FSC (Figure 3b). The maximum along channel velocities $(>10 \mathrm{~cm} / \mathrm{s})$ in the FSC are present in the top $200 \mathrm{~m}$ and are seen toward the middle of the channel while observations (1995-2009 mean) suggest maximum along-channel velocities $(>20 \mathrm{~cm} / \mathrm{s})$ to be present more toward the Scottish shelf edge (Berx et al., 2013). A part of the inflow in the FSC branches off into the North Sea and is seen in Figure $3 \mathrm{c}$ as a depth-independent broad inflow. On this North Sea section, the inflow has its highest intensity west of the western Norwegian Trench (between 300 and $400 \mathrm{~km}$, east of Scottish east coast). The Norwegian Trench shows outflow waters from surface down to the bottom. The model gives an outflow on the shallower western parts of the Norwegian Trench where an inflow is know to be present. The long-term (1850-2005) mean volume transport through the FSC in in this model is $5.5 \mathrm{~Sv}$, which is higher than observed short-term estimates of 3.5 to $4 \mathrm{~Sv}$ (Berx et al., 2013). The total northern inflow into the North Sea is about 1.6 Sv, which is close to known estimates of 1.7 to $2 \mathrm{~Sv}$ (Hjøllo et al., 2009). This suggests that while challenges remain, the model is in overall agreement with respect to the location and intensity of various inflows.

The continuity of the saline core of Atlantic water into the Rockall Trough and FSC and finally into the North Sea raises questions about the source of high salinity in the model. That the saline core moves close to the shelf edge points to the region south of Rockall Trough as a potential source region and the ESC as the conduit. A property-property diagram of a region south of Rockall Trough and west of Bay of Biscay is shown in Figure 4. This region is selected as it sits in the intergyre region between the SPG and the subtropical gyre. 
(a)

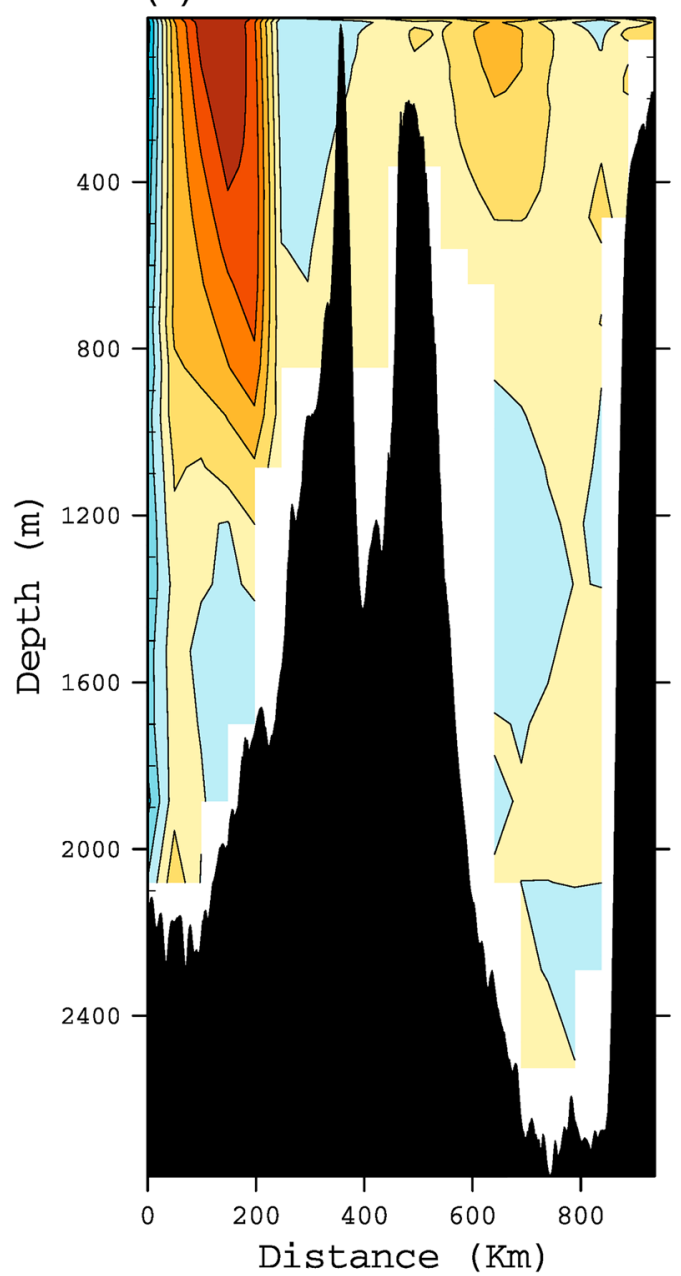

(b)

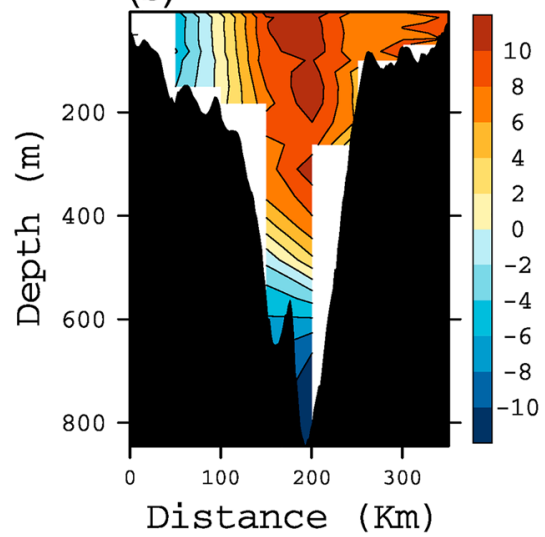

(c)

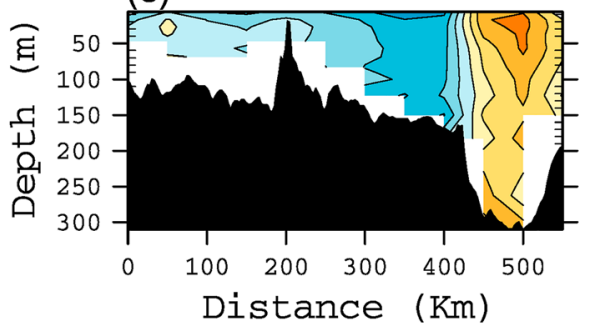

Figure 3. Velocity (cm/s) perpendicular to a section across (a) Rockall Trough, (b) Faroe-Scotland Channel, and at (c) North Sea entrance. For Rockall Trough and Faroe-Scotland Channel, $u$ component of the velocity is shown, and for North Sea, $v$ component is shown.

Two salinity maxima are seen in the temperature-salinity (T-S) diagram, a shallower one at about $360 \mathrm{~m}$ and the deeper one at about $900 \mathrm{~m}$. The upper salinity maximum has salinity exceeding $35.70 \mathrm{psu}$, the highest at these latitudes and therefore, this highly saline water is considered here as the model equivalent of ENAW. The deeper salinity maximum $\left(\sigma_{0}=27.3\right)$, with a corresponding oxygen minimum, is a vestige of MOW as seen in another T-S analysis south of $40^{\circ} \mathrm{N}$ (figure not shown), which is also known to propagate northward (Lozier \& Stewart, 2008; Sarafanov et al., 2008). Further analysis shows that both salinity maxima merge north of $50^{\circ} \mathrm{N}$ and enter the Rockall Trough as a single saline core. The salinity of this modeled saline core diminishes downstream as it mixes with ambient water masses of subpolar origin.

In summary, MPI-ESM1.2-LR reproduces surface and subsurface salinity, circulation, and inflow characteristics in the eastern North Atlantic and the North Sea. Challenges remain, however, near the shallower southern and eastern parts of the North Sea. Nevertheless, we only focus on the northern parts of the North Sea and the eastern North Atlantic, where the model is able to reproduce major currents and the associated spreading of North Atlantic water masses. In subsequent sections, we analyze how the variability in the northward penetration of the saline core of Atlantic inflow depends on SPG strength.

\section{Results}

\subsection{The SPG Strength and Salinity Variations in Eastern North Atlantic}

The SPG circulation is coupled to atmospheric variability and the overturning circulation. The dynamical changes in the SPG are captured by the leading mode of SSH variability in the North Atlantic, which explains 

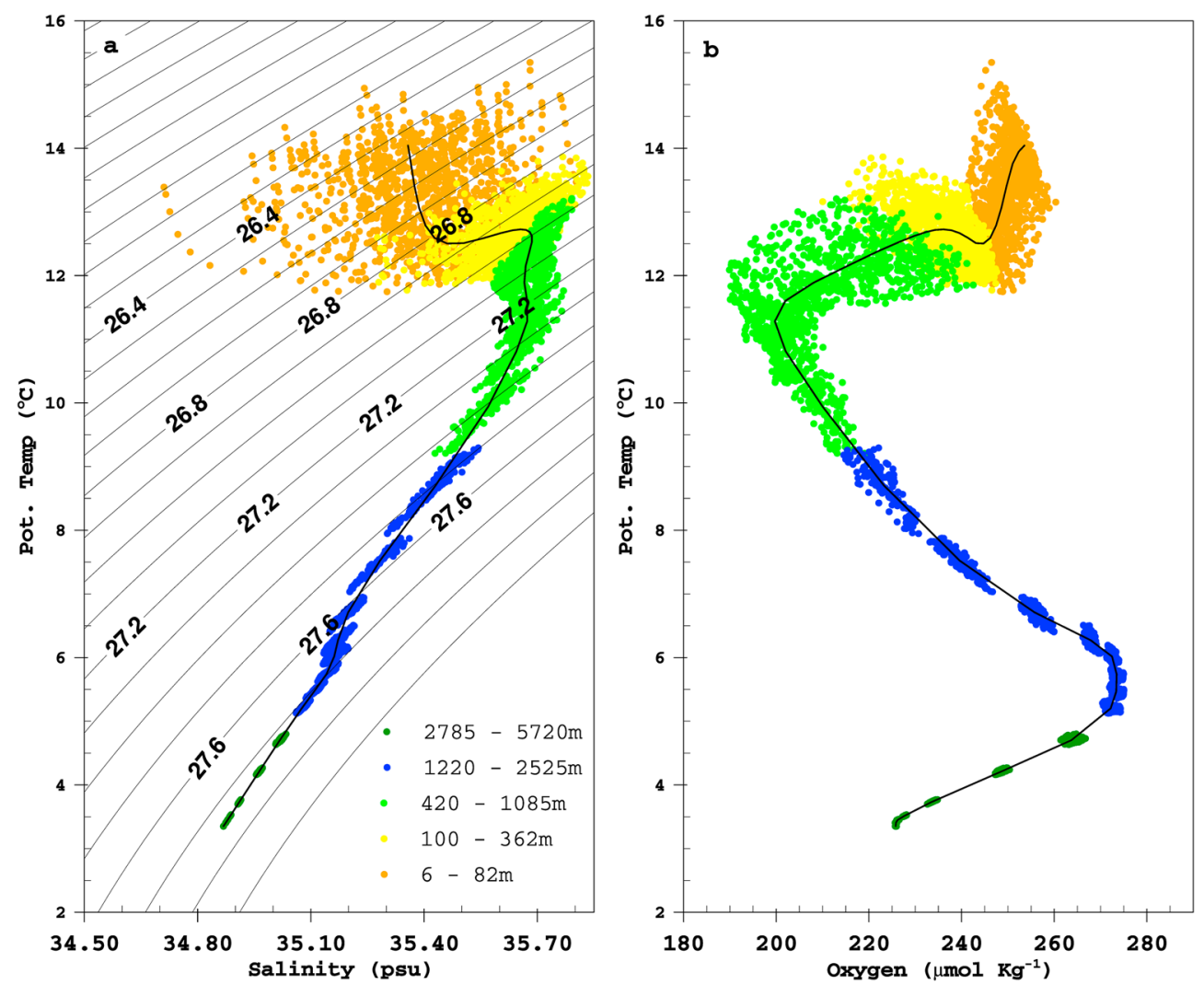

Figure 4. (a) Temperature-salinity and (b) temperature-oxygen diagram for the region south of Rockall Trough and west of Bay of Biscay $\left(12-20^{\circ} \mathrm{W}, 42-50^{\circ} \mathrm{N}\right)$. In the left panel, a salinity maximum is seen at depths shallower than $500 \mathrm{~m}$; this is the model equivalent of the highly saline Eastern North Atlantic water.

$20 \%$ of total variance in this simulation (Figure 5a) and resembles to some extent the well-known dipole pattern seen in both observations (Häkkinen \& Rhines, 2004) and simulation with a general circulation model (Zhang, 2008). A large part of the variability associated with this pattern is present along the Gulf Stream (GS)/NAC region, while some part of the variability is also seen in the southeastern periphery and the SPG center with a tendency opposite to that of the GS/NAC region. Note that the weights in the GS/NAC region are stronger than those presented in earlier studies (Häkkinen \& Rhines, 2004; Zhang, 2008). Further analysis reveals that in this model simulation, the southern boundary of the SPG undergoes profound meridional shifts in the Newfoundland basin, which are captured by this leading mode, and thus strong weighting is present along the GS/NAC path.

The evolution of the SPG strength in MPI-ESM1.2-LR (Figure 5b) is consistent with the present understanding of evolution of heat and currents in the subpolar North Atlantic. The reduction of upper SPG heat content (densification) and the lowering of SSH at the gyre center both indicate a strengthening gyre and vice versa (Häkkinen \& Rhines, 2004). That the temporal evolution of the leading mode of the SSH variability in the North Atlantic $\left(0-70^{\circ} \mathrm{W}, 30-65^{\circ} \mathrm{N}\right)$ in our model simulation is robust is further confirmed by the high correlation between the SPGI and upper ocean heat content of the SPG $\left(10-60^{\circ} \mathrm{W}, 50-62^{\circ} \mathrm{N}\right.$; Table 1$)$.

To test the relationship between the SPGI and salinity in the eastern North Atlantic, we perform a composite analysis of top 500-m average salinity for strong and weak SPG states (Figure 6). The freshening in the Iceland Basin and Rockall Trough is concomitant with a strengthening SPG, which facilitates the eastward extension of fresh subpolar water masses (Figure 6a). On the other hand, the westward retreat of fresh upper layer concomitant with a weakening SPG circulation allows subtropical waters to dominate this region and propagate far northward across the ISR (Figure 6b). The changes in the SPG structure, however subtle, become clearer when the isolines of SSH are compared (contour lines in Figures 6a and 6b). The westward retreat of isolines of SSH in the eastern North Atlantic signifies a contracted SPG. This limits the eastward extension of subpolar water masses that would otherwise counter the influence of subtropical water masses 

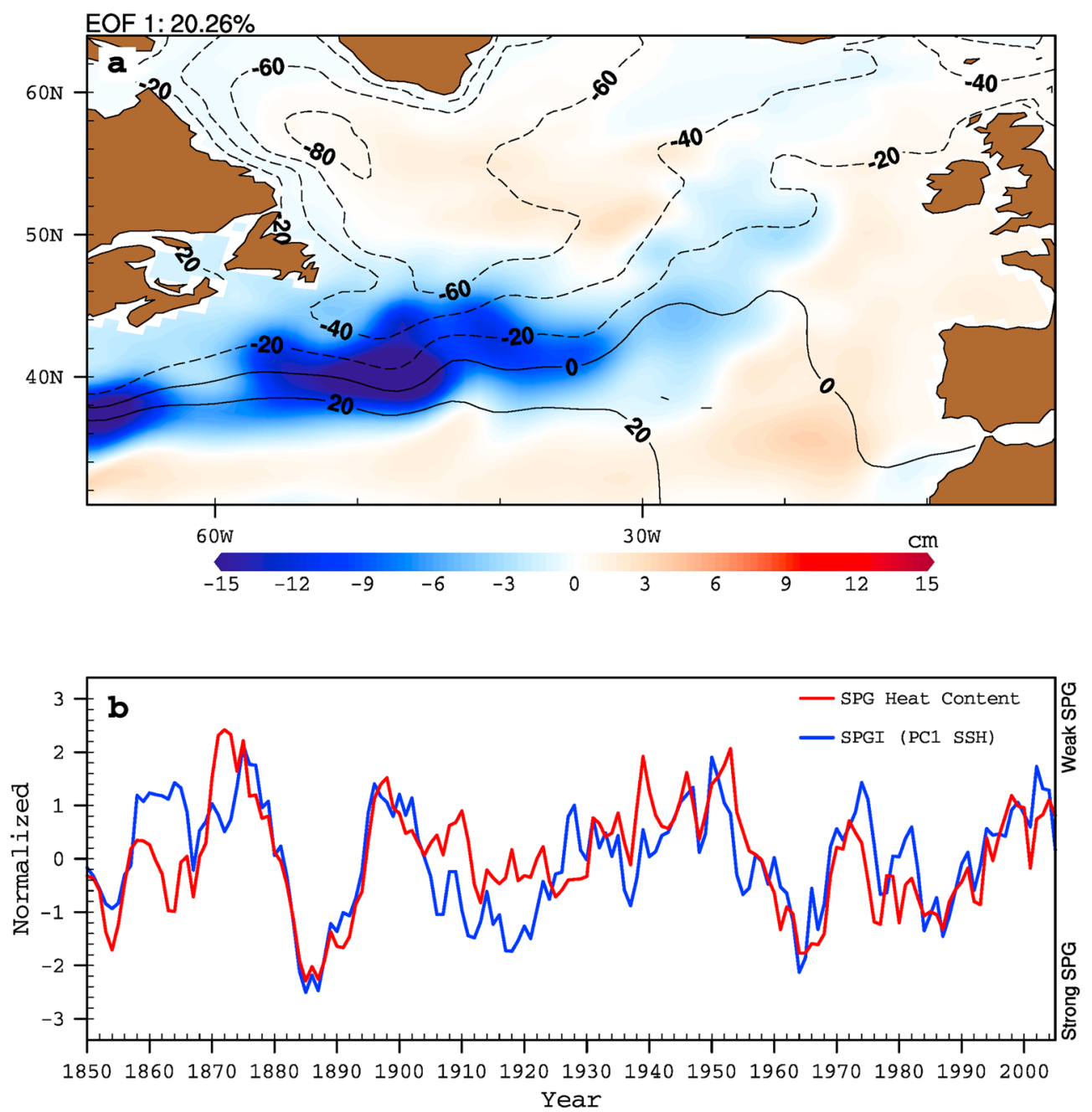

Figure 5. (a) The pattern of the first empirical orthogonal function (EOF) of the sea surface height (SSH) anomalies in the North Atlantic. Overlayed black lines are the mean SSH contours. (b) Time series (normalized) of the subpolar gyre (SPG) heat content of top $700 \mathrm{~m}$ and the SPG index (SPGI). The heat content is averaged over the domain: $\left(10-60^{\circ} \mathrm{W}\right.$, $\left.50-62^{\circ} \mathrm{N}\right)$.

(Bersch et al., 2007; Hátún et al., 2005). Therefore, the Rockall Trough, the FSC, and northern North Sea all have a saline upper layer regime when the SPG is weak, and the SPGI captures this connection. From the North Sea perspective, the SPGI thus represents the temporal evolution of large-scale oceanic variability upstream of the ISR, the impact of which is investigated further.

The composite analysis of the relation between the SPGI and the upper layer salinity in the region of interest does not provide information regarding consistency in time. To this extent, we show propagation of upper-layer salinity along a section (black line in Figure 2d) from northern Rockall Trough to central North Sea through the FSC (Figure 7a). The simulation shows periods of saline and low saline influence on this section. The recurring high salinity pulses and their persistence for 5 to 10 years in some cases indicates the presence of a low-frequency driving mechanism likely of Atlantic origin. The slope (about 1 year of propagation time from Rockall Trough to northern North Sea) of these pulses also indicates that they originate south of the ISR (Figure 7b). This is consistent with the observational study of Glessmer et al. (2014) who showed that in recent decades freshwater anomalies in the Nordic Sea originated south of ISR, while the role of freshwater anomalies from the Arctic was not substantial. To check if the salinity anomalies on this section are a result of concomitant changes in the local flow field, we look at current speed anomalies on the same section (Figure 7c). This figure depicts that as compared to salinity anomalies, current speed anomalies vary at a much faster rate. Except during the period 1880-1890, there is no other indication of 
Table 1

Pearson's Correlation Coefficients ( $r$ ) Among Various Variables, the Lag at Which r is Maximum (Lag), the Estimated Degree of Freedom (df) and the Associated $p$ Value (p) Based on Two-Tailed t Test

\begin{tabular}{|c|c|c|c|c|c|c|c|c|}
\hline \multirow[b]{2}{*}{ (lr)Var1 } & \multirow[b]{2}{*}{ Var2 } & \multicolumn{6}{|c|}{ Unfiltered } & \multirow{2}{*}{$\begin{array}{c}\text { 10-Year Low-Pass Filtered } \\
\qquad r^{*}\end{array}$} \\
\hline & & Lag & $d f$ & $r$ & $p$ & Lag* & $r^{*}$ & \\
\hline \multirow[t]{8}{*}{ SPGI } & SPG heat content & 0 & 48 & 0.71 & 0.000001 & $0[0,1]$ & $\mathbf{0 . 7 1}[0.53,0.83]$ & $\mathbf{0 . 7 4}[0.51,0.87]$ \\
\hline & FSC inflow & 0 & 63 & 0.12 & 0.3489 & & $0.13[-0.07,0.36]$ & $0.26[-0.08,0.58]$ \\
\hline & FSC Saline inflow & 1 & 27 & 0.66 & 0.0002 & $0[0,2]$ & $\mathbf{0 . 6 4}[0.47,0.77]$ & $\mathbf{0 . 8 2}[0.66,0.91]$ \\
\hline & NS inflow & 2 & 116 & 0.21 & 0.0236 & & $0.16[-0.02,0.35]$ & $0.33[-0.07,0.61]$ \\
\hline & NS Saline inflow & 2 & 48 & 0.45 & 0.00133 & $0[0,4]$ & $\mathbf{0 . 3 7}[0.11,0.57]$ & $\mathbf{0 . 6 5}[0.35,0.88]$ \\
\hline & RT Salinity & 1 & 40 & 0.37 & 0.0187 & $0[0,2]$ & $0.35[0.12,0.55]$ & $\mathbf{0 . 4 9}[0.22,0.71]$ \\
\hline & FSC Salinity & 1 & 37 & 0.53 & 0.0007 & $0[0,2]$ & $\mathbf{0 . 5 1}[0.34,0.66]$ & $\mathbf{0 . 7 1}[0.52,0.83]$ \\
\hline & NS Salinity & 3 & 56 & 0.42 & 0.0013 & $2[0,5]$ & $\mathbf{0 . 2 8}[0.08,0.46]$ & $\mathbf{0 . 4 7}[0.16,0.73]$ \\
\hline NS inflow & NS Salinity & 0 & 111 & 0.34 & 0.0003 & $0[0,2]$ & $\mathbf{0 . 3 4}[0.20,0.46]$ & $\mathbf{0 . 3 7}[0.09,0.60]$ \\
\hline \multirow[t]{2}{*}{ RT Salinity } & FSC Salinity & 1 & 48 & 0.49 & 0.0004 & $0[0,2]$ & $\mathbf{0 . 4 3}[0.23,0.60]$ & $\mathbf{0 . 6 4}[0.46,0.77]$ \\
\hline & NS Salinity & 1 & 66 & 0.49 & 0.00003 & $1[0,3]$ & $\mathbf{0 . 3 9}[0.19,0.54]$ & $\mathbf{0 . 6 1}[0.34,0.77]$ \\
\hline FSC Salinity & NS Salinity & 1 & 53 & 0.39 & 0.0039 & $1[0,3]$ & $\mathbf{0 . 3 4}[0.13,0.53]$ & $\mathbf{0 . 5 4}[0.32,0.72]$ \\
\hline
\end{tabular}

Note. Median value of the block bootstrapped Pearson's correlation coefficients $\left(r^{*}\right)$ and the lag at which $r^{*}$ is maximum (Lag*). The numbers in square brackets give the uncertainty range. Uncertainty in lag is estimated only for those variables that are statistically significantly correlated (bold). FSC $=$ Faroe-Shetland Channel; SPG = subpolar gyre; SPGI = SPG index.

covariance between salinity and current speed anomalies. This implies that salinity anomalies have to be tracked upstream to find their generation mechanism.

Salinity (top $100 \mathrm{~m}$ ) in the FSC and northern North Sea largely follows variability in Rockall Trough salinity (Figure 8a). The correlation coefficients increase when the data are filtered with a 10-year low-pass filter (Table 1). The correlations and the time series themselves suggests that it is the decadal to multidecadal variability that is pronounced. On interannual timescale, there are few instances of incoherent deviations, particulaly after mid-1990s. The correlation between unfiltered Rockall Trough and northern North Sea salinity ( $r=0.49$, at lag 1 year with Rockall Trough leading, also see Table 1 ) is higher than between FSC and North Sea ( $r=0.39$, at lag 1 year with FSC leading). This is consistent with observations-based study of Núñez-Riboni and Akimova (2017) who also found a lag of 1 year in salinity anomalies from Rockall Trough to northern North Sea. This implies a close coupling between Rockall Trough and North Sea in the model, which is also suggested by earlier observations (Holliday \& Reid, 2001). In the FSC, water masses are transformed due to additional influence of water masses from Faroe Current and mixing with fresh
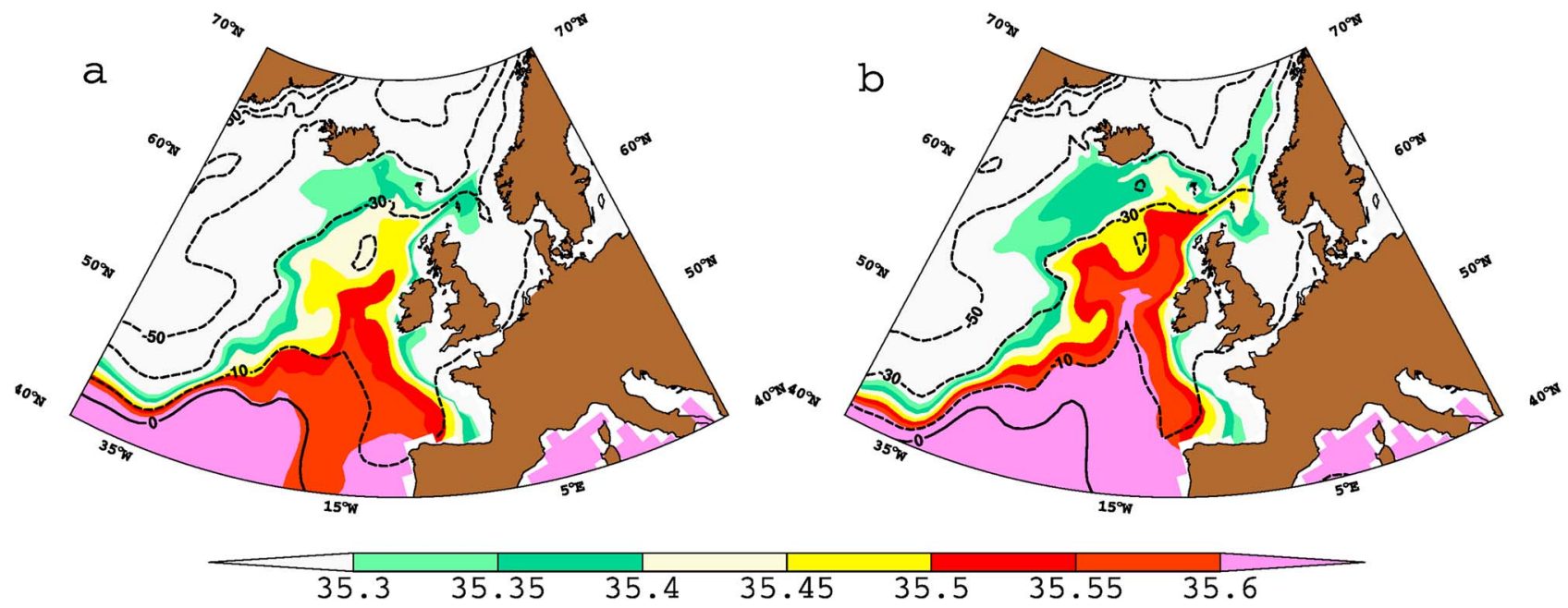

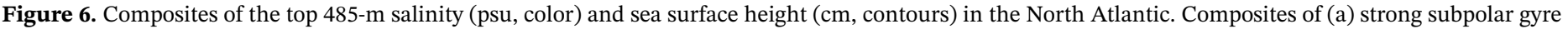
(SPG) and (b) weak SPG are based on \pm 1 standard deviation of SPG index. 

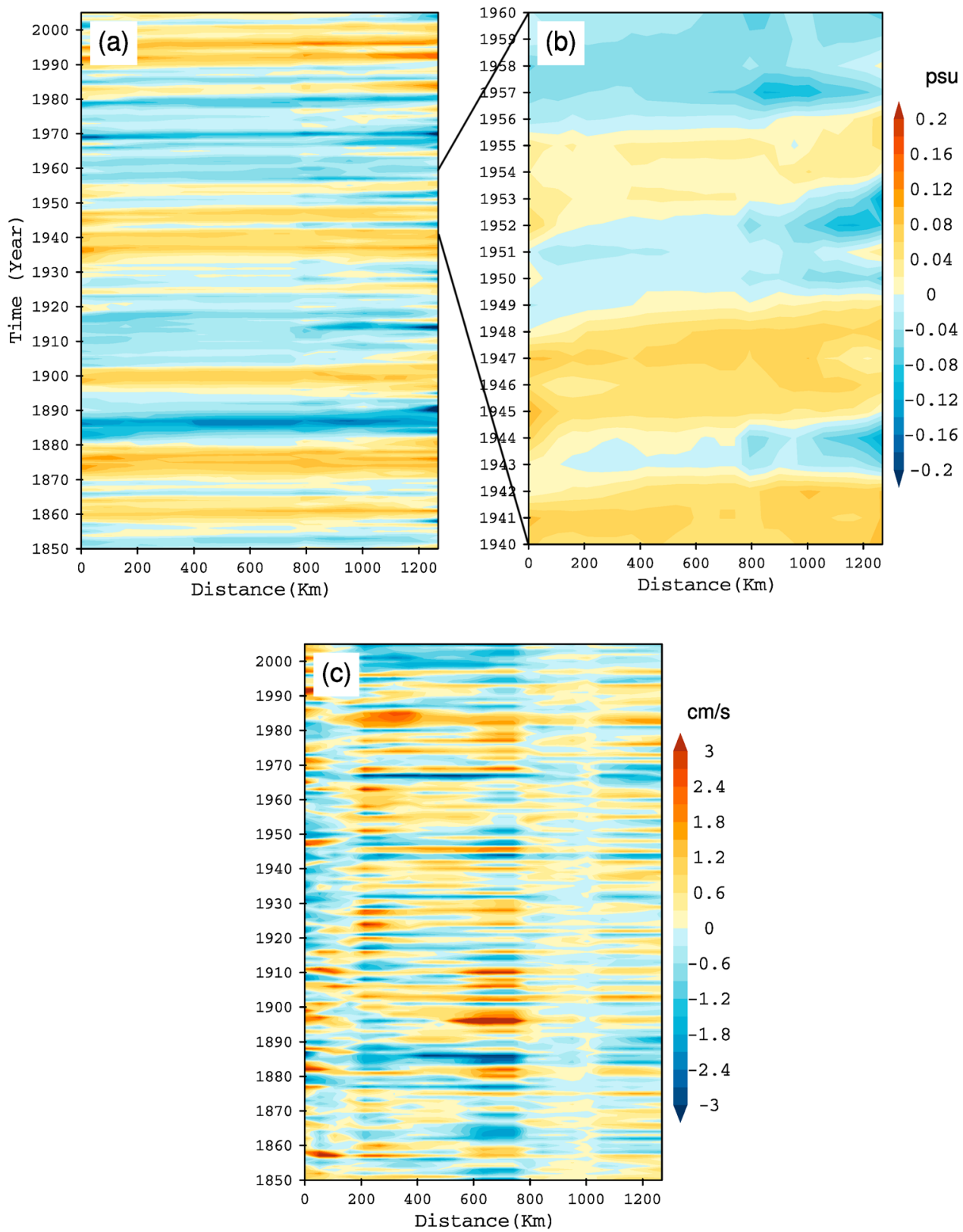

Figure 7. Hovmöller diagram for top 100-m average (a) salinity (psu) and (b) current speed $(\mathrm{cm} / \mathrm{s}$ ) anomalies along the section from Rockall Trough $(0 \mathrm{~km})$ to the central North Sea shown in Figure 2d (complete black line). Points on the section shallower than $100 \mathrm{~m}$ are averaged down to bottom.

intermediate waters offshore of Scotland (Turrell et al., 2003). These water mass transformation processes would account for the reduced correlations with the North Sea salinity if these induce distinct modes of variability. Otherwise, atmospheric variability (FSC is shallower than Rockall Trough) could be the cause of reduced correlations between FSC and the North Sea.

A spatial picture of regional covariance between Rockall Trough salinity and the NWES is illustrated in Figures $8 \mathrm{~b}$ and $8 \mathrm{c}$. At lag 0 year, maximum correlations are limited to the south of ISR. At lag 1 year, maximum correlations are seen along the shelf edge of the NWES. Also, the positive correlations in the North Sea move southward and eastward at lag 1 year. Thus, these spatial correlation patterns confirm the advective pathway of Atlantic water from the Rockall Trough to the northern North Sea in this global model (Figure 1a). 

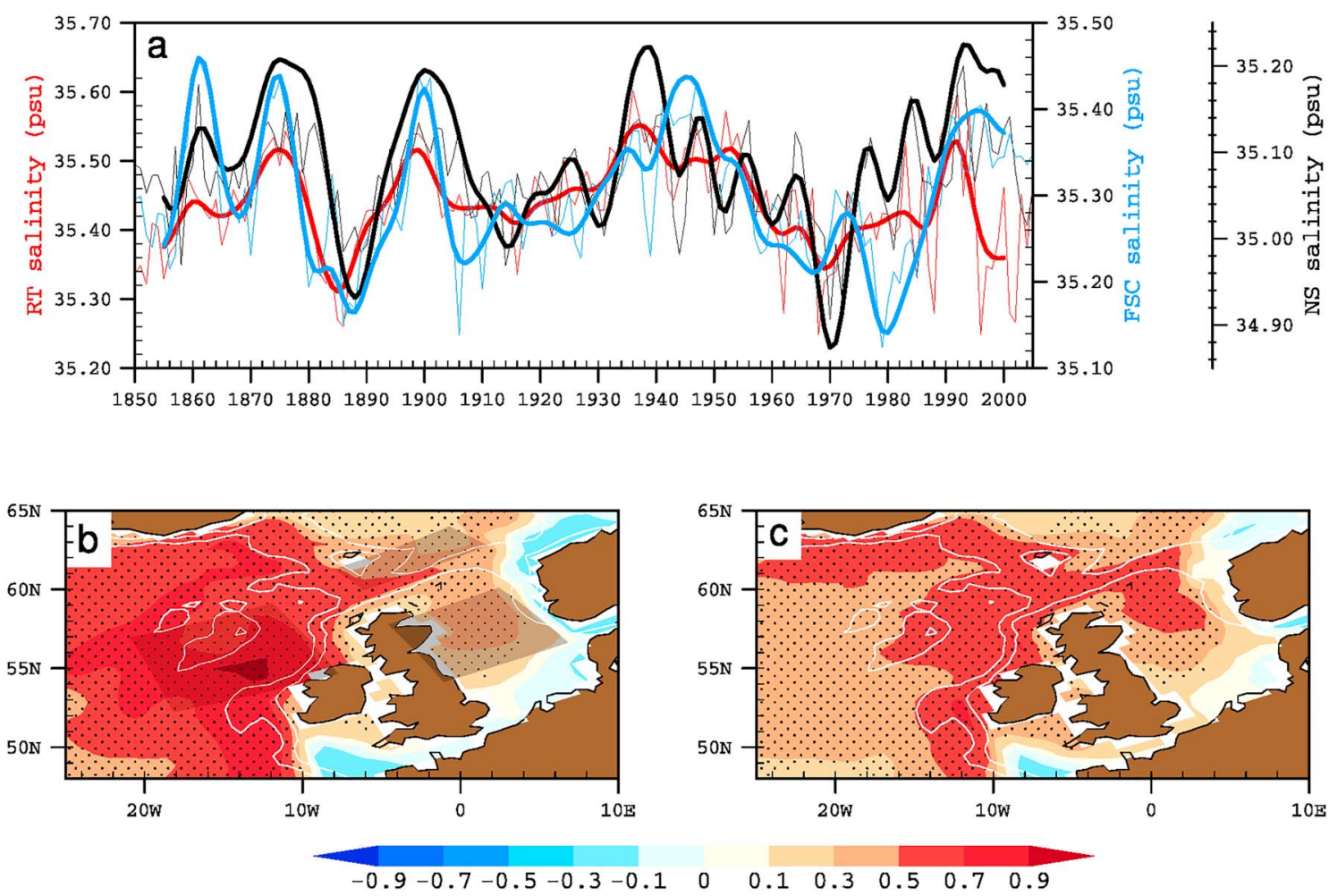

Figure 8. (a) Time series (Interannual, thin lines and 10-year low pass filtered, thick lines) of top 100-m average salinity (psu) in the Rockall Trough (RT), the Faroe-Scotland Channel, and northern North Sea (NS). (b) Correlation between the Rockall Trough salinity time series and top 100-m average salinity at each grid point at lag 0 year. The shaded regions show the respective areas over which the salinity is averaged to get the time series shown in Figure 8a. (c) Same as Figure $8 \mathrm{~b}$ but at lag 1 year. The striplings in Figures $8 \mathrm{~b}$ and $8 \mathrm{c}$ represent statistically significant values at $95 \%$ confidence level. The thin white lines in Figures $8 \mathrm{~b}$ and $8 \mathrm{c}$ are the $200-$ and $1,000-\mathrm{m}$ isobaths.

\subsection{Hydrographic and Transport Variability}

Having illustrated an influence of SPG strength on northward penetration of subtropical waters, we now focus on the subsurface variability in the key regions and its connection with volume transport variability. In the Rockall Trough, the intermediate layer (1,200-2,000 m) appears to be out of phase with the upper ocean in its response to the change in the SPG state (Figure 9a). At these depths, LSW is present (cyclonic recirculation at 1,200-1,600 $\mathrm{m}$ in Figure 3a). And it is known from observations that in the eastern North Atlantic, LSW salinity is out of phase with the upper layers because here it evolves at a much slower rate due to long transit times involved in its transport from the Labrador Sea (Bersch et al., 2007). The sill depth of ISR near FSC is about $500 \mathrm{~m}$; therefore, we expect only the top 500-700 $\mathrm{m}$ of the water column to allow for northward propagation of salinity anomalies associated with the SPG. Concomitant with a weakening SPG, most of the salinification is seen above $500 \mathrm{~m}$ and is most likely the result of higher amounts of modeled ENAW.

In the FSC, salinity increase is seen throughout the water column with highest amplitudes in the inflow layers (Figure 9b, also see Figure 3b for inflow layers). As these composites are based on annual means, the salinity increase in the deep layers which mainly have southward moving dense overflow is very likely due to mixing. The reason being that when the inflowing high-salinity water recirculates in this region and strong winter cooling deepens the mixed layer, the surface salinity signal can reach deeper layers. A part of Atlantic inflow through the FSC flows into the North Sea, so this salinity increase is also expected in the northern North Sea. The salinity increase is indeed seen in the northern and central North Sea, while the southern and eastern parts have an opposite tendency (Figures 9c and 9d). The southern and eastern parts of the North Sea are dominated by inflows from the English Channel and Baltic Sea in the upper layers and hence do not reflect the connection with the SPG.

Now we assess changes in water mass characteristics into the Rockall Trough, the FSC, and and North Sea in relation to the SPG strength. Water mass definitions based on observations cannot be used due to model biases and errors; hence, we first assess changes in the volume in T-S space (Figure 10). In line with results 
(a)

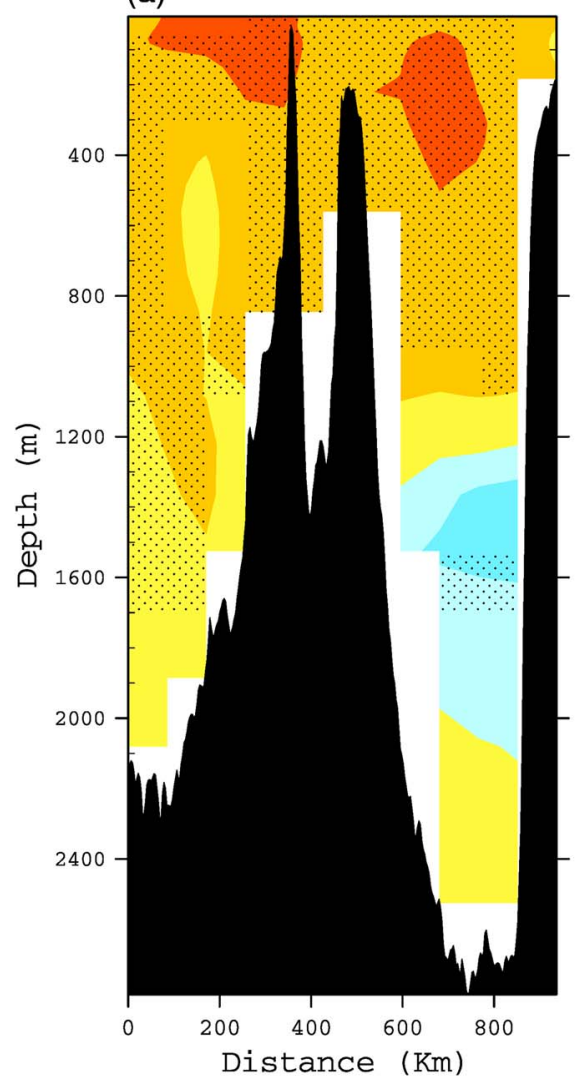

(b)

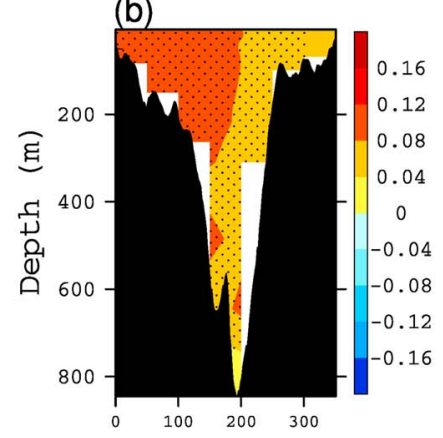

(c)

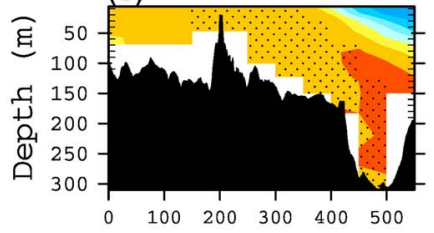

(d)

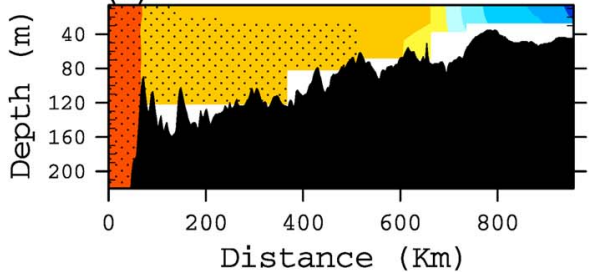

Figure 9. Composite difference (weak-strong SPG) of salinity (psu) for the section across (a) Rockall Trough, (b) FSC, at the (c) North Sea entrance, and through (d) center of North Sea (part of the black line in Figure 2d from the shelf edge to the central North Sea). Location of all sections is shown in Figure 2d. The striplings represent statistically significant values at $95 \%$ confidence level.

presented earlier, Rockall Trough has a large volume of warm saline water in the upper layers when the SPG is weak and vice versa (Figure 10a). This also points to the origin of respective water masses: Volume changes are mostly concentrated either in the warm saline part in the T-S space indicating a subtropical origin or in the cold fresh part indicating a subpolar origin. In the FSC, volume changes occur over a wide range of temperature and salinity (Figure 10b). Moreover, high amplitudes of SPG-related temperature changes are mainly limited to the layers with $T>9.5^{\circ} \mathrm{C}$, while salinity increase covers the entire channel. As for the northern North Sea, this region is much shallower compared to the other two regions, and hence, seasonal heating and winds obscure the SPG signal here. Nevertheless, Figure 10c does indicate a tendency of North Sea property changes to follow those of Rockall Trough and FSC. Here again, salinity differences are more pronounced than corresponding temperature differences.
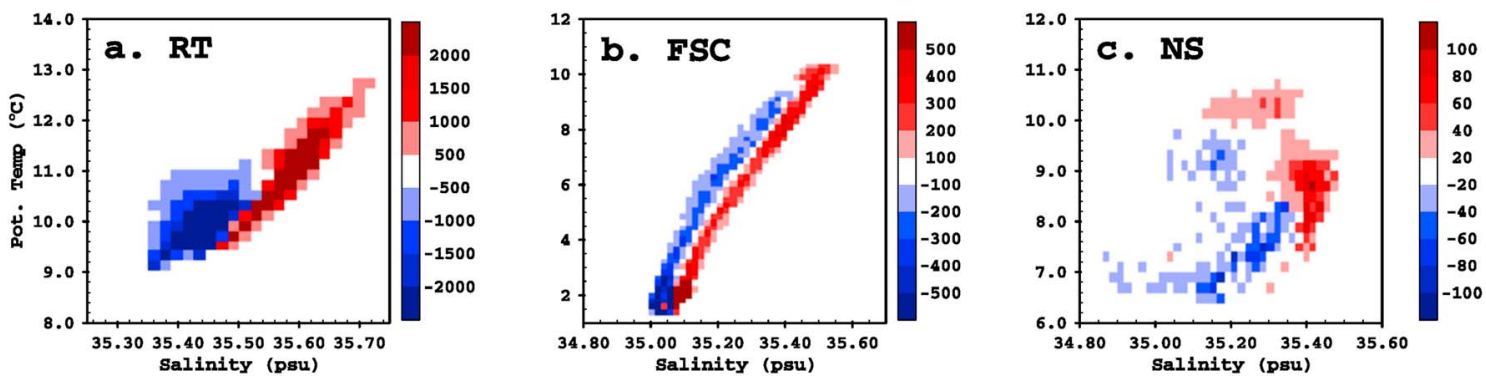

Figure 10. Composite difference (weak-strong subpolar gyre) of top 960-m water volume ( $\mathrm{km}^{3}$ ) for (a) Rockall Trough (RT), (b) Faroe-Shetland Channel (FSC), and (c) northern North Sea (NS). For FSC and northern NS, depth is down to bottom. The respective regions are shown in Figure 8b. 

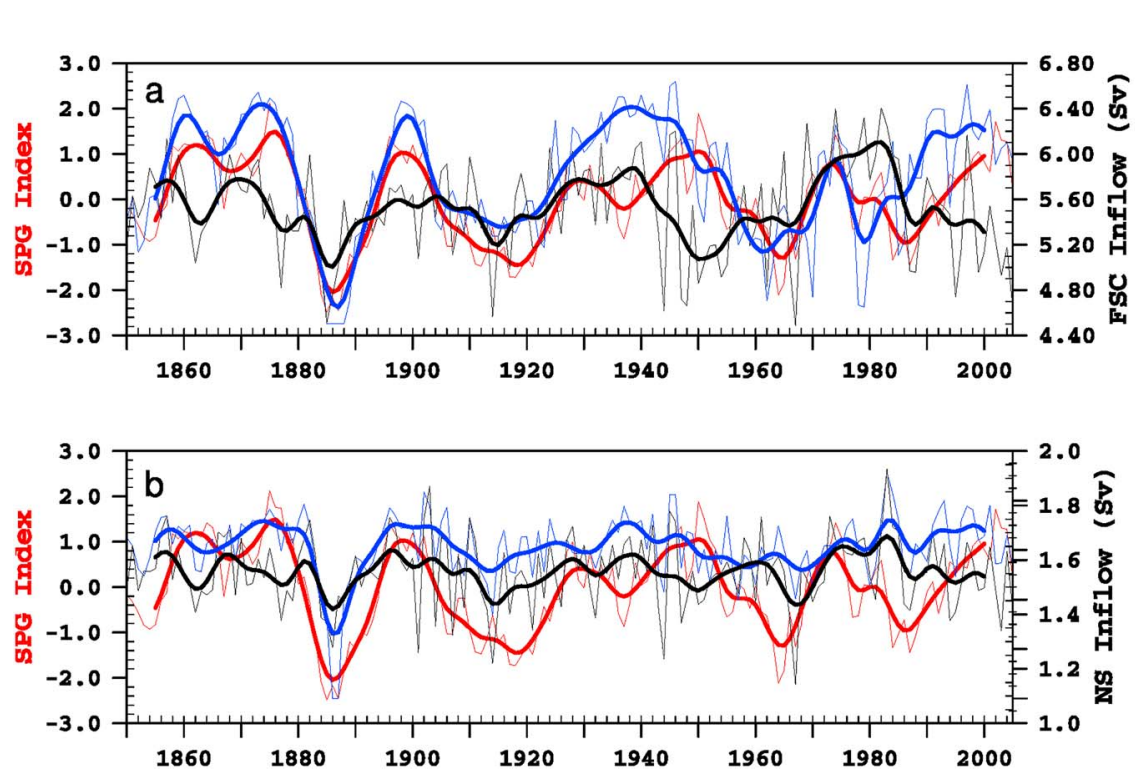

Figure 11. Time series (Interannual, thin lines and 10-year low pass filtered, thick lines) of subpolar gyre (SPG) index and volume transports into (a) Faroe-Scotland Channel (FSC) and (b) North Sea (NS). The total volume transport (inflow) comprises all water masses with northward velocities into the FSC (across yellow line in Figure 2d) and southward into the NS (approximately across blue line in Figure 2d). The "saline" volume transport (saline inflow) is that part of total inflow with salinity $>35.40$ psu for the FSC and salinity $>35.30$ psu for the NS.

The volumetric water mass analysis illustrates an important aspect of subsurface fingerprint of SPG circulation variability. For example, in the northern North Sea, we see that only a part of the water column is impacted coherently, and rather than temperature, most of the information about forcing history is in salinity. This now allows us to define a water mass and to quantify changes in its volume transport through the FSC and northern North Sea (Figure 11). We define the "total" inflow as the volume transport of all northward flowing water into the FSC and all southward flowing water into the North Sea. The "saline" inflow refers to that part of total volume transport with salinity greater than a certain threshold (35.40 psu for FSC and 35.30 psu for North Sea), which marks the approximate boundary of volume changes (Figure 10). The total volume transport into both FSC and North Sea is not significantly correlated with the SPGI (Table 1) and is marked by strong interannual variability. On the other hand, the saline inflow through FSC and North Sea is significantly correlated with SPGI ( $r=0.64$ and 0.37 , respectively). For the North Sea, the change in correlation when only high-salinity ( $>35.30 \mathrm{psu}$ ) water is considered is not large but nevertheless significant. Note that the "total" and "saline" inflow through North Sea have a coefficient of determination $\left(r^{2}\right)$ of about $45 \%$, suggesting that for the North Sea, large part of inflow has high frequency variability. There is a 1-year lag between the SPGI and FSC saline inflow and a 2-year lag with the North Sea saline inflow. The uncertainty associated with the lag identified between the SPGI and North Sea Saline inflow suggests that it is within 4 years that the impact of changes in SPG circulation is identified the North Sea. This includes the 1-year propagation time of salinity anomalies from the Rockall Trough to the North Sea.

The coherence of SPGI with the FSC saline inflow peaks at period longer than 20 years (Figure 12a), and with the North Sea Saline inflow, the statistically significant period is between 30 and 40 years (Figure 12b). Thus, in this model simulation, it is the decadal to multidecadal variability in the SPG circulation that influences the saline inflow into these two regions. Also, the relatively high correlation between SPGI and North Sea salinity (section 3.1) as compared to the correlation between North Sea total inflow and North Sea salinity at decadal timescales and beyond (Table 1) suggests that at least at these timescales, the salinity in North Sea follows SPG variability rather than local acceleration of inflow.

\subsection{Role of Atmospheric Variability}

While we have illustrated that part of the inflow into the FSC and North Sea is influenced by the SPG circulation, a detailed analysis of total FSC and North Sea inflow hints at the role of local atmospheric forcing. 

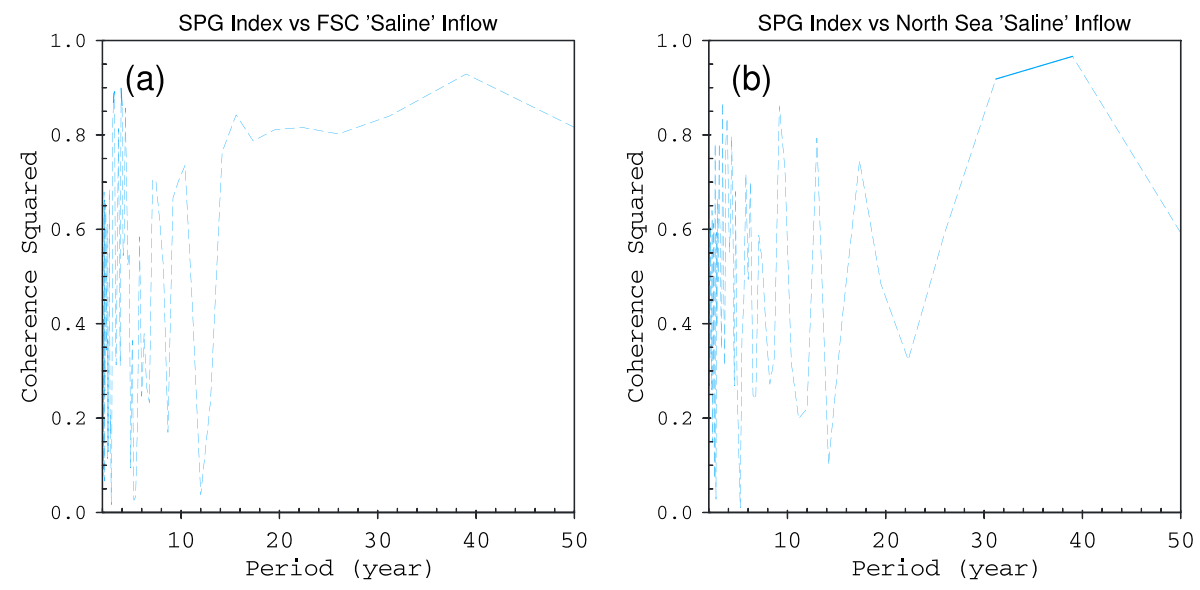

Figure 12. Square of the spectral coherence between subpolar gyre (SPG) index and (a) Faroe-Scotland Channel (FSC) saline inflow and (b) North Sea saline inflow. Statistically significant values at $95 \%$ confidence level are represented by bold solid line.

Figure 13 illustrates that the total North Sea inflow is linked to the winds. Periods of strong Atlantic inflow to the North Sea are concomitant with periods of strong southwesterly wind flow. The mean sea level pressure pattern associated with a strong North Sea inflow results in southwesterly winds that pile water onto the shelf through a strong Ekman transport. Similar analysis of relationship between North Sea saline inflow and atmospheric variability shows similar pressure and wind pattern but with lower amplitudes (figure not shown). This suggests that part of the variability in saline inflow not explained by SPGI is explained by atmospheric variability. For the FSC, however, low amplitudes of the pressure pattern in Figure 13a suggest that the mechanisms driving the total FSC inflow are not entirely wind related (see, for example, Sandø et al., 2012).

The impact of large-scale atmospheric variability on the NWES is now investigated through a regression analysis (Figure 14). The large-scale atmospheric patterns in the North Atlantic in this simulation resemble the North Atlantic Oscillation (NAO; Figure 14a) and the East Atlantic Pattern (EAP; Figure 14b). Over the NWES region, positive NAO is associated with westerly winds (Figure 14c). Consistent with earlier analysis, westerly winds lead to an increased inflow of Atlantic water across the shelf break, and thus SSH increases in the North Sea (positive regression coefficients), particularly the southern part. That the fresh Baltic outflow into the North Sea is also restricted due to westerly winds is confirmed by the strong salinification in

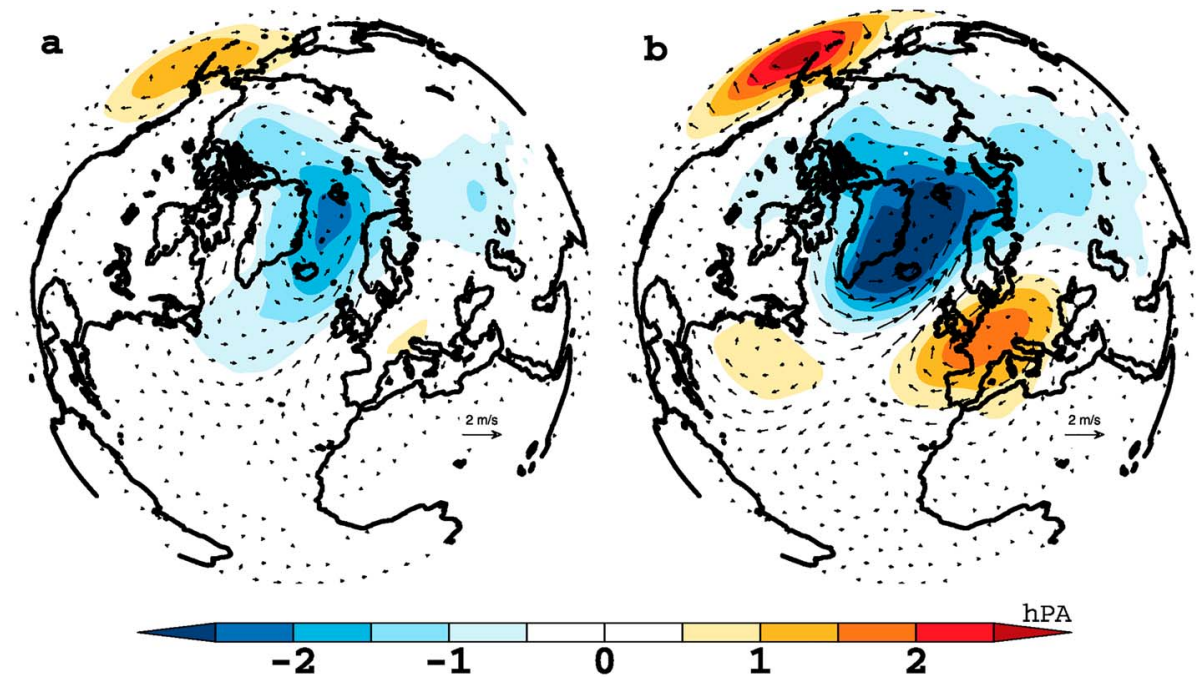

Figure 13. Composite difference of mean sea level pressure ( $\mathrm{hPa}$, color) and 10-m winds ( $\mathrm{m} / \mathrm{s}$, arrows) for total (a) strong-weak FSC inflow and (b) strong-weak North Sea inflow. 

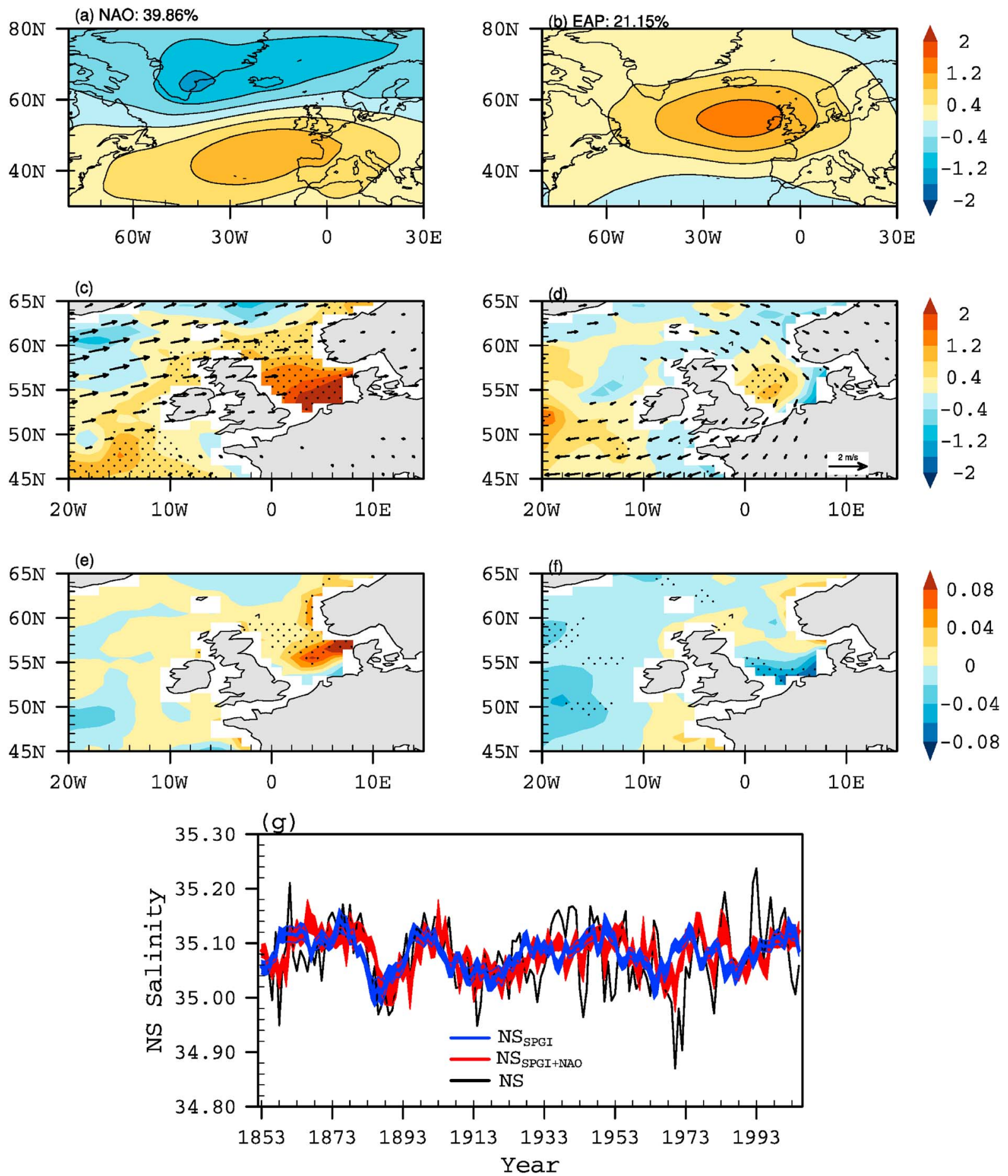

Figure 14. Modes of variabililty of Mean Sea Level Pressure (MSLP). (a) EOF1 (North Atlantic Oscillation [NAO]) and (b) EOF2 (East Atlantic Pattern [EAP]). Regression of 10-m winds (m/s, arrows) and sea surface height (cm, contours) on normalized (c) NAO (PC1 of MSLP) and (d) EAP (PC2 MSLP) index. Regression of salinity (psu) on normalized (e) NAO and (f) EAP index. Only statistically significant regression coefficients are shown (for winds) and stippled (for filled contours). (g) Time series of North Sea (NS) salinity (black line), reconstructed NS salinity from regression coefficients based on subpolar gyre index (SPGI; blue line), and NAO and SPGI combined (red line). The thickness of blue and red lines denotes the $95 \%$ confidence bounds. 
the Baltic outflow region and along the Norwegian Trench. Thus, a positive NAO leads to an increase in salinity in the North Sea (Figure 14e) with no lag involved. On the other hand, the atmospheric wind pattern associated with the EAP is such that it has no significant impact on either the Atlantic inflow or the fresh Baltic outflow. As a consequence, there is no significant impact of EAP on salinity in the northern North Sea (Figure 14f).

As the direct influence of the NAO on North Sea salinity is through the atmospheric winds, the NAO mainly explains short-term (interannual) variability in the North Sea salinity time series. This is illustrated through comparison of reconstructed North Sea salinity time series using SPGI and NAO as predictors (Figure 14g). The regression coefficients are estimated from the time period 1853-1950, and thereafter, the same regression coefficients are used to reconstruct North Sea salinity for the time period 1951-2005 (see section 2.2). Quite clearly, short-term variations in North Sea salinity are captured by that regression model that includes NAO as one of the predictors. On the other hand, long-term (decadal to multidecadal) variations are largely explained by the regression model based on SPGI alone (SPGI leads North Sea salinity by 3 years, see Table 1), which confirms the impact of oceanic variability associated with the SPG circulation on long-term variations in North Sea salinity.

\section{Discussion}

We began with the following question: What part of the variability in the North Sea is of Atlantic origin? This question could not have been investigated using a regional model because regional models of the North Sea tend to discount open-ocean signals at their boundaries. This is due to the issues associated with specifying lateral open boundary conditions. Therefore, the nature of the question at hand and the focus on decadal to multidecadal timescales facilitates the usage of a global model.

The inflowing Atlantic water properties and its transport play a critical role in North Sea variability at timescales longer than those dominated by internal North Sea processes. This remote oceanic control on North Sea was already suggested by Holt et al. (2012) who showed that lateral transport of Atlantic water deficient in nutrient content is an important constraint on primary production. Such realization, therefore, opens up the scope for global models to be used for studying open ocean influence on North Sea via advection of anomalies of remote oceanic origin. However, along with the important prerequisite of being able to resolve broader North Sea circulation characteristics satisfactorily, such analysis using global models would have to be limited to timescales longer than flushing time ( $>1$ year) of the North Sea.

In this study, using a century-long simulation with a global model, we showed that large-scale open-ocean circulation has an impact on North Sea inflow. However, there are some caveats that must be considered while interpreting these results. First, we have not assessed the impact of local processes on water mass properties from the Rockall Trough to the North Sea. Second, we have also not looked into the role of changes in the source water mass properties in the North Atlantic, for example, in the Labrador Sea or in the vicinity of Bay of Biscay. This analysis also excludes the shallower southern parts of the North Sea where local processes internal to the North Sea are dominant. In these parts of the North Sea, river runoff and tidal mixing dominate. Also, our results are derived from a single model, it would be interesting to examine if other global coupled models show similar SPG-North Sea connections.

Coming back to the results presented in this study, we note that several processes might act together or individually lead to increased salinity levels in the North Sea. These are (a) increased volume transport of Atlantic water, (b) increased salinity of the Atlantic water, and (c) imbalance in the large-scale evaporation minus precipitation $(\mathrm{E}-\mathrm{P}$ ) field. As the focus of the present study is on those regions of the North Sea that are away from the coast, river runoff can be excluded as a potential cause. As far as the role of large-scale $\mathrm{E}-\mathrm{P}$ field is concerned, the advective delays from the Rockall Trough rule out that possibility as well. This is because changes in the large-scale $\mathrm{E}-\mathrm{P}$ field would lead to concurrent changes in the surface salinity in the Rockall Trough, the FSC, and North Sea, which we do not find in our analysis. The large-scale E - P field can however enhance or suppress the open ocean signal.

In the present analysis, we identify periods of elevated salinity levels in the Rockall Trough, the FSC, and the northern North Sea in our simulation, and we show that the recurring high saline periods in these regions are due to the increase in salinity of the Atlantic inflow and not due to the acceleration of the inflow. Although interannual variability in salinity in the NWES region has often been linked to variability in volume transport 
(Ellett \& Turrell, 1992; Hjøllo et al., 2009; Sundby \& Drinkwater, 2007), the persistence of salinity anomalies for multiple years and their recurrence is difficult to explain through changes in volume transport only. One such example is the gradual increase and persistence of high salinity for more than 3 years in the late 1950s in the NWES, which was studied by Dickson (1971). Since his analysis had allowed him to neglect the role of E - P field and river runoff, he had to either show that the volume transport for those years was also increasing from year to year and/or that the source water masses recruited in the inflow stream had a more southern origin than normal. A persistent pressure anomaly pattern and the resulting air-sea feedback processes were thus conjectured as the mechanism that allowed sustained advective interventions in the eastern North Atlantic, which then resulted in increased "southernliness" of the water masses entering the inflow stream to the NWES. However, given observational constraints, it was not still clear if the increased salinity was also due to actual acceleration of the inflow.

The question then arises: Why are there periods of high salinity anomalies in the absence of high volume transport anomalies in this simulation? The mechanism identified as the cause of recurring and persistent salinification is the quasiperiodic variability in SPG strength. The "southerliness" of the source water masses is found to be due to higher throughput of subtropical water during those periods when the SPG is weak. Thus, water masses of subtropical origin entering the Atlantic inflow dominate those of subpolar origin, which would then lead to elevated salinity levels. Becker et al. (1997) also found peak spectral power between 15 to 20 years in long-term temperature and salinity time series of various regions in the NWES. They attributed those spectral peaks to "long-period fluctuations in the North Atlantic circulation system." They speculated that a varying interaction between the SPG and subtropical gyre could lead to elevated salinity levels in the NWES. In the present study, we find that long-period fluctuations in the North Atlantic circulation system of 30- to 40-year period are closely related to the strength in the SPG circulation.

Another important aspect of our results is related to the interpretation of the EOF1 mode. The EOF1 mode presented by Häkkinen and Rhines (2004) was based on a short altimeter record and hence does not capture decadal to multidecadal variability associated with the NAC/GS position. Strong weights in the NAC/GS region in the present simulation indicate that meridional shifts in the NAC/GS position lead to heat content changes in the SPG, which then spins up/spins down the SPG circulation (see, for example, Zhang, 2008), and the concomitant reorganization of major current pathways (i.e., expansion and contraction of SPG circulation) in the eastern North Atlantic leads to salinity changes in the NWES. Causes of the meridional shifts in the NAC/GS position and its relationship with the SPG strength are not investigated further in the present paper.

We also show that the atmospheric variability influences North Sea salinity. The direct impact of NAO leads to salinification in the North Sea, while the EAP has no significant impact on North Sea salinity in this simulation. It is important to note that while the direct influence of NAO on North Sea salinity is limited to short-term variations, NAO can also influence North Sea salinity indirectly through its influence on oceanic circulation in the subpolar North Atlantic. We have not investigated this aspect further in this study; however, we conjecture that the indirect influence of NAO would be opposite to its direct influence. This is because a positive NAO tendency over multiple years leads to strengthening of the SPG circulation, which would then lead to freshening in the eastern North Atlantic and the northern North Sea.

\section{Conclusions}

Based on our analysis of the connections between the subpolar North Atlantic and the North Sea in a historical simulation with the MPI-ESM-LR, we conclude that

- A low-frequency oceanic perturbation of Atlantic origin drives the reoccurrence and persistence of high salinity pulses on a section from Rockall Trough to the North Sea. In all three regions examined, the Rockall Trough, the FSC, and the northern North Sea, salinity varies coherently, albeit with advective delays. The advective delay from the Rockall Trough to the northern North Sea is found to be about 1 year.

- At decadal timescales, the leading mode of SSH variability (20\% explained variance in this simulation) captures the earlier reported eastern North Atlantic salinity and SPG strength connection.

- While the total volume transport of Atlantic water into the North Sea is wind driven and does not covary with SPG strength, the properties of the inflowing Atlantic water are modulated by the variability in SPG strength at decadal to multidecadal timescales (30- to 40-year period). 
The SPG-driven changes in salinity in the eastern North Atlantic and the northern North Sea can influence local hydrographic variability by influencing stratification (Núñez-Riboni \& Akimova, 2017) and also influence marine ecosystems in the Rockall Trough (Miesner \& Payne, 2018) and the North Sea (Akimova et al., 2016). It also remains to be seen if the influence of SPG variability is present in nutrient concentrations with potential implications for North Sea marine ecosystems. As we have identified oceanic (SPG-driven) impacts on the North Sea and as SPG variability has been shown to be predictable with state-of-the-art decadal prediction system at multiyear lead times (Robson et al., 2012), there might in turn be a potential for the North Sea system too. Current decadal prediction systems are all based on global coupled models. Assessment of such initialized global coupled model simulations in the eastern North Atlantic and in the northern North Sea would illuminate whether the open ocean impacts revealed in the present study also translate into a significant prediction skill.

\section{Acknowledgments}

This work has benefited from stimulating discussions with Manfred Bersch and technical help from Helmuth Haak. This work was was funded through a research collaboration between Helmholtz Zentrum Geesthacht and Universität Hamburg. The work of J. B. and A. D. was supported by the Cluster of Excellence CliSAP (EXC177), Universität Hamburg, funded through the Deutsche Forschungsgemeinschaft (DFG, German Research Foundation). This work was also funded by the DFG under Germanys Excellence Strategy EXC 2037 "Climate, Climatic Change, and Society" Project 390683824 , contribution to the Center for Earth System Research and Sustainability (CEN) of Universitt Hamburg (J. B. and A. D.). The authors thank Michael Botzet for carrying out the model simulations. The authors also thank three anonymous reviewers whose comments greatly improved the manuscript. The authors also thank the German Computing Center (DKRZ) for providing their computing resources. Model data are accessible at the DKRZ (www.dkrz.de/up). The authors do not report any conflict of interest.

\section{References}

Akimova, A., Nunez-Riboni, I., Kempf, A., \& Taylor, M. H. (2016). Spatially-resolved influence of temperature and salinity on stock and recruitment variability of commercially important fishes in the North Sea. PloS one, 11(9), e0161917.

Alheit, J., Licandro, P., Coombs, S., Garcia, A., Giráldez, A., Santamaría, M. T. G., et al. (2014). Reprint of Atlantic Multidecadal Oscillation (AMO) modulates dynamics of small pelagic fishes and ecosystem regime shifts in the eastern North and Central Atlantic. Journal of Marine Systems, 133, 88-102.

Böning, C. W., Scheinert, M., Dengg, J., Biastoch, A., \& Funk, A. (2006). Decadal variability of subpolar gyre transport and its reverberation in the North Atlantic overturning. Geophysical Research Letters, 33, L21S01. https://doi.org/10.1029/2006GL026906

Becker, G., \& Dooley, H. (1995). The 1989/91 high salinity anomaly in the North Sea and adjacent areas. Ocean Challenge-Challenger Society for Marine Science, 6, 52-57.

Becker, G. A., Frohse, A., \& Damm, P. (1997). The northwest European shelf temperature and salinity variability. Ocean Dynamics, 49(2), $135-151$.

Bersch, M. (2002). North Atlantic Oscillation-induced changes of the upper layer circulation in the northern North Atlantic Ocean. Journal of Geophysical Research, 107(C10), 3156.

Bersch, M., Yashayaev, I., \& Koltermann, K. P. (2007). Recent changes of the thermohaline circulation in the subpolar North Atlantic. Ocean Dynamics, 57(3), 223-235.

Berx, B., Hansen, B., Østerhus, S., Larsen, K., Sherwin, T., \& Jochumsen, K. (2013). Combining in situ measurements and altimetry to estimate volume, heat and salt transport variability through the Faroe-Shetland Channel. Ocean Science, 9(4), 639-654.

Daewel, U., \& Schrum, C. (2017). Low-frequency variability in North Sea and Baltic Sea identified through simulations with the 3-D coupled physical-biogeochemical model ECOSMO. Earth System Dynamics, 8(3), 801.

Dickson, R. R. (1971). A recurrent and persistent pressure-anomaly pattern as the principal cause of intermediate-scale hydrographic variation in the European shelf seas. Deutsche Hydrografische Zeitschrift, 24(3), 97-119.

Ellett, D., \& Turrell, W. (1992). Increased salinity levels in the NE Atlantic. ICES Council Meeting Papers, ICES, Copenhagen (Denmark), $1992,12$.

Foukal, N. P., \& Lozier, M. S. (2017). Assessing variability in the size and strength of the North Atlantic subpolar gyre. Journal of Geophysical Research: Oceans, 122, 6295-6308. https://doi.org/10.1002/2017JC012798

Gent, P. R., Willebrand, J., McDougall, T. J., \& McWilliams, J. C. (1995). Parameterizing eddy-induced tracer transports in ocean circulation models. Journal of Physical Oceanography, 25(4), 463-474.

Glessmer, M. S., Eldevik, T., Våge, K., Nilsen, J. E. Ø., \& Behrens, E. (2014). Atlantic origin of observed and modelled freshwater anomalies in the Nordic Seas. Nature Geoscience, 7(11), 801.

Hagemann, S., \& Gates, L. D. (2003). Improving a subgrid runoff parameterization scheme for climate models by the use of high resolution data derived from satellite observations. Climate Dynamics, 21(3-4), 349-359.

Häkkinen, S., \& Rhines, P. B. (2004). Decline of subpolar North Atlantic circulation during the 1990s. Science, 304(5670), 555-559.

Hátún, H., \& Chafik, L. (2018). On the recent ambiguity of the north atlantic subpolar gyre index. Journal of Geophysical Research: Oceans, 123, 5072-5076. https://doi.org/10.1029/2018JC014101

Hátún, H., Sandø, A. B., Drange, H., Hansen, B., \& Valdimarsson, H. (2005). Influence of the Atlantic subpolar gyre on the thermohaline circulation. Science, 309(5742), 1841-1844.

Hjøllo, S. S., Skogen, M. D., \& Svendsen, E. (2009). Exploring currents and heat within the North Sea using a numerical model. Journal of Marine Systems, 78(1), 180-192.

Holliday, N. (2003). Air-sea interaction and circulation changes in the northeast Atlantic. Journal of Geophysical Research, 108 (C8), 3259. https://doi.org/10.1029/2002JC001344

Holliday, N., Cunningham, S., Johnson, C., Gary, S., Griffiths, C., Read, J., \& Sherwin, T. (2015). Multidecadal variability of potential temperature, salinity, and transport in the eastern subpolar North Atlantic. Journal of Geophysical Research: Oceans, $120,5945-5967$. https://doi.org/10.1002/2015JC010762

Holliday, N. P., \& Reid, P. C. (2001). Is there a connection between high transport of water through he Rockall Trough and ecological changes in the North Sea? ICES Journal of Marine Science: Journal du Conseil, 58(1), 270-274.

Holt, J., Butenschon, M., Wakelin, S., Artioli, Y., \& Allen, J. (2012). Oceanic controls on the primary production of the northwest European continental shelf: Model experiments under recent past conditions and a potential future scenario. Biogeosciences, 9, 97-117.

Ilyina, T., Six, K. D., Segschneider, J., Maier-Reimer, E., Li, H., \& Núñez-Riboni, I. (2013). Global ocean biogeochemistry model HAMOCC: Model architecture and performance as component of the MPI-Earth system model in different CMIP5 experimental realizations. Journal of Advances in Modeling Earth Systems, 5, 287-315. https://doi.org/10.1029/2012MS000178

Johnson, C., Inall, M., \& Häkkinen, S. (2013). Declining nutrient concentrations in the northeast Atlantic as a result of a weakening subpolar gyre. Deep Sea Research Part I: Oceanographic Research Papers, 82, 95-107. 
Jungclaus, J., Fischer, N., Haak, H., Lohmann, K., Marotzke, J., Matei, D., et al. (2013). Characteristics of the ocean simulations in the Max Planck Institute Ocean Model (MPIOM) the ocean component of the MPI-Earth system model. Journal of Advances in Modeling Earth Systems, 5, 422-446. https://doi.org/10.1002/jame.20023

Langford, S., Stevenson, S., \& Noone, D. (2014). Analysis of low-frequency precipitation variability in CMIP5 historical simulations for southwestern North America. Journal of Climate, 27(7), 2735-2756.

Lozier, M. S., \& Stewart, N. M. (2008). On the temporally varying northward penetration of Mediterranean overflow water and eastward penetration of Labrador Sea water. Journal of Physical Oceanography, 38, 2097-2103.

Marsland, S. J., Haak, H., Jungclaus, J. H., Latif, M., \& Röske, F. (2003). The Max-Planck-Institute global ocean/sea ice model with orthogonal curvilinear coordinates. Ocean Modelling, 5(2), 91-127.

Martin, E. R., Thorncroft, C., \& Booth, B. B. (2014). The multidecadal Atlantic SST-Sahel rainfall teleconnection in CMIP5 simulations. Journal of Climate, 27(2), 784-806.

Mathis, M., Elizalde, A., \& Mikolajewicz, U. (2017). Which complexity of regional climate system models is essential for downscaling anthropogenic climate change in the Northwest European Shelf? Climate Dynamics, 50, 2637-2659.

McCarthy, G. D., Haigh, I. D., Hirschi, J. J.-M., Grist, J. P., \& Smeed, D. A. (2015). Ocean impact on decadal Atlantic climate variability revealed by sea-level observations. Nature, 521(7553), 508-510.

Miesner, A. K., \& Payne, M. R. (2018). Oceanographic variability shapes the spawning distribution of blue whiting (Micromesistius poutassou). Fisheries Oceanography, 27, 623-638.

Núñez-Riboni, I., \& Akimova, A. (2017). Quantifying the impact of the major driving mechanisms of inter-annual variability of salinity in the North Sea. Progress in Oceanography, 154, 25-37.

Orvik, K. A., \& Niiler, P. (2002). Major pathways of Atlantic water in the northern North Atlantic and Nordic Seas toward Arctic. Geophysical Research Letters, 29(19), 1896. https://doi.org/10.1029/2002GL015002

Pacanowski, R., \& Philander, S. (1981). Parameterization of vertical mixing in numerical models of tropical oceans. Journal of Physical Oceanography, 11(11), 1443-1451.

Pätsch, J., Burchard, H., Dieterich, C., Gräwe, U., Gröger, M., Mathis, M., et al. (2017). An evaluation of the North Sea circulation in global and regional models relevant for ecosystem simulations. Ocean Modelling, 116, 70-95.

Pyper, B. J., \& Peterman, R. M. (1998). Comparison of methods to account for autocorrelation in correlation analyses of fish data. Canadian Journal of Fisheries and Aquatic Sciences, 55(9), 2127-2140.

Reick, C., Raddatz, T., Brovkin, V., \& Gayler, V. (2013). Representation of natural and anthropogenic land cover change in MPI-ESM. Journal of Advances in Modeling Earth Systems, 5, 459-482. https://doi.org/10.1002/jame.20022

Robson, J., Sutton, R., \& Smith, D. (2012). Initialized decadal predictions of the rapid warming of the North Atlantic Ocean in the mid 1990s. Geophysical Research Letters, 39, L19713. https://doi.org/10.1029/2012GL053370

Sandø, A., Nilsen, J., Eldevik, T., \& Bentsen, M. (2012). Mechanisms for variable North Atlantic-Nordic seas exchanges. Journal of Geophysical Research, 117, C12006. https://doi.org/10.1029/2012JC008177

Sarafanov, A., Falina, A., Sokov, A., \& Demidov, A. (2008). Intense warming and salinification of intermediate waters of southern origin in the eastern subpolar North Atlantic in the 1990s to mid-2000s. Journal of Geophysical Research, 113, C12022. https://doi.org/10.1029/2008JC004975

Sherwin, T. J., Read, J. F., Holliday, N. P., \& Johnson, C. (2011). The impact of changes in North Atlantic Gyre distribution on water mass characteristics in the Rockall Trough. ICES Journal of Marine Science, 69(5), 751-757.

Stevens, B., Giorgetta, M., Esch, M., Mauritsen, T., Crueger, T., Rast, S., et al. (2013). Atmospheric component of the MPI-M Earth System Model: ECHAM6. Journal of Advances in Modeling Earth Systems, 5, 146-172. https://doi.org/10.1002/jame.20015

Sundby, S., \& Drinkwater, K. (2007). On the mechanisms behind salinity anomaly signals of the northern North Atlantic. Progress in Oceanography, 73(2), 190-202.

Turrell, W. R., Hansen, B., Hughes, S., \& Østerhus, S. (2003). Hydrographic variability during the decade of the 1990s in the Northeast Atlantic and southern Norwegian Sea. In Ices marine science symposia, Vol. 219, pp. 111-120.

Turrell, W., Slesser, G., Payne, R., Adams, R., \& Gillibrand, P. (1996). Hydrography of the East Shetland Basin in relation to decadal North Sea variability. ICES Journal of Marine Science: Journal du Conseil, 53(6), 899-916.

Winther, N. G., \& Johannessen, J. A. (2006). North Sea circulation: Atlantic inflow and its destination. Journal of Geophysical Research, 111, C12018. https://doi.org/10.1029/2005JC003310

Zhang, R. (2008). Coherent surface-subsurface fingerprint of the Atlantic meridional overturning circulation. Geophysical Research Letters, 35, L20705. https://doi.org/10.1029/2008GL035463

Zhang, L., \& Wang, C. (2013). Multidecadal North Atlantic sea surface temperature and Atlantic meridional overturning circulation variability in CMIP5 historical simulations. Journal of Geophysical Research: Oceans, 118, 5772-5791. https://doi.org/10.1002/jgrc.20390 